\title{
A systematic review of mental health outcome measures for young people aged 12 to 25 years
}

Benjamin Kwan ${ }^{1 *}$ and Debra J. Rickwood ${ }^{1,2}$

\begin{abstract}
Background: Mental health outcome measures are used to monitor the quality and effectiveness of mental health services. There is also a growing expectation for implementation of routine measurement and measures being used by clinicians as a feedback monitoring system to improve client outcomes. The recent focus in Australia and elsewhere targeting mental health services to young people aged 12-25 years has meant that outcome measures relevant to this age range are now needed. This is a shift from the traditional divide of child and adolescent services versus adult services with a transitioning age at 18 years. This systematic review is the first to examine mental health outcome measures that are appropriate for the 12 to 25 year age range.

Methods: MEDLINE and PsychINFO databases were systematically searched to identify studies using mental health outcome measures with young people aged 12 to 25 years. The search strategy complied with the relevant sections of the PRISMA statement.

Results: A total of 184 published articles were identified, covering 29 different outcome measures. The measures were organised into domains that consisted of eight measures of cognition and emotion, nine functioning measures, six quality of life measures, and six multidimensional mental health measures. No measures were designed specifically for young people aged 12 to 25 years and only two had been used by clinicians as a feedback monitoring system. Five measures had been used across the whole 12 to 25 year age range, in a range of mental health settings and were deemed most appropriate for this age group.

Conclusions: With changes to mental health service systems that increasingly focus on early intervention in adolescence and young adulthood, there is a need for outcome measures designed specifically for those aged 12 to 25 years. In particular, multidimensional measures that are clinically meaningful need to be developed to ensure quality and effectiveness in youth mental health. Additionally, outcome measures can be clinically useful when designed to be used within routine feedback monitoring systems.
\end{abstract}

Keywords: Youth, Young people, Mental health, Change, Routine outcome measure, Feedback

\section{Background}

An outcome measure in mental health care can be defined as a tool used to measure the effect on a person's mental health as a result of health care intervention, plus any additional extra-therapeutic influences [1]. Specifically, outcome measures are quantitative indicators used at two or more points in time: baseline, post-

\footnotetext{
*Correspondence: ben.kwan@canberra.edu.au

${ }^{1}$ Faculty of Health, University of Canberra, Kirinari Street, Bruce, ACT 2601, Australia

Full list of author information is available at the end of the article
}

intervention, discharge, or follow-ups [2, 3]. Routine outcome measurement, whereby the same outcome measure is used frequently at a number of time points, has been adopted in child and adolescent mental health services in Australia, New Zealand, Denmark, United Kingdom and Norway [4]. This push has been driven by an increasing emphasis on monitoring the quality and effectiveness of services $[5,6]$.

Routine outcome measurement reported at the service level enables decision making around funding of services, particularly at a government level where health

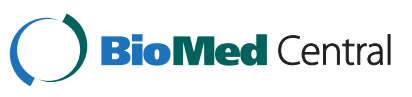

(C) 2015 Kwan and Rickwood. Open Access This article is distributed under the terms of the Creative Commons Attribution 4.0 International License (http://creativecommons.org/licenses/by/4.0/), which permits unrestricted use, distribution, and reproduction in any medium, provided you give appropriate credit to the original author(s) and the source, provide a link to the Creative Commons license, and indicate if changes were made. The Creative Commons Public Domain Dedication waiver (http://creativecommons.org/publicdomain/zero/1.0/) applies to the data made available in this article, unless otherwise stated. 
resources are limited and need to be distributed to achieve the best outcomes [4]. It is also essential as a component of ongoing service-level quality improvement. Importantly, routine outcome measurement improves clinical practice when it is part of a feedback monitoring system for clinicians [7]. When mental health measures are regularly provided to the clinician they can inform clinical decision making and enable the clinician to adjust treatment planning accordingly [8]. In adult mental health services feedback has been shown to increase accuracy of diagnosis, improve communication between client and clinician, enhance treatment monitoring, and help clients maintain positive effects for longer periods $[9,10]$. For clients who are not improving or who are deteriorating during therapy, feedback systems can help improve outcomes [9]. Emerging research in youth mental health contexts suggests similar benefits of feedback monitoring systems for younger clients $[11,12]$.

To be useful, mental health outcome measures must be valid and reliable, sensitive to change, comparable across relevant client groups and service types, and meaningful to both clients and clinicians [6]. Fundamentally, outcome measures must be sensitive to change and be able to clearly convey the magnitude of change achieved [13]. However, measuring change is complex and needs to go beyond reporting statistical significance. Effect sizes and the timescale in which the change is evident are essential [14]. An increasingly used technique is calculating a measure of reliable change, which takes into account the reliability of the measurement instrument and has been proposed to provide a more accurate standard of meaningful change [15, 16]. Additionally, estimating clinical significance, which is distinct from statistical significance, has been recommended in mental health contexts. Change is clinically significant when a client moves from the dysfunctional to the functional range during therapy. This technique is not commonly used as it requires comparison populations and norms [17]. These metric are useful, however, as a client can be considered "recovered" when their outcomes show both reliable change and clinical significance [16]. Meaningful changes are also those that are of value and considered important by the client, family or clinician $[18,19]$. Notably, quantifiable change can be different from perceived change, which means that it is important to determine outcome measures that are personally meaningful to clients [20].

Outcome measures need to be comparable over relevant client groups and treatment settings, and help inform initial case formulation and client prioritisation access. Outcome measures are increasingly designed to measure broad mental health status rather than assess symptoms associated with the diagnosis of specific mental disorders [21]. Specific measures may be required for diagnosis, but are not helpful when making comparisons between cases and services where differences in case mix exist [22]. Using specific diagnostic measures also means clinicians need to isolate a particular presenting problem at baseline to assess subsequent change. This presents challenges for the common situations when clients have comorbid mental health issues or their presenting issues change over the course of therapy $[11,23]$. In contrast, measures of general mental health can be used in a range of mental health settings with different client characteristics, including public mental health agencies, private organisations, schools, and hospitals. Being generically relevant to a broad range of mental health presentations enables the measure to cater for clients with no disorder, such as those accessing prevention mental health programs, through to those with severe disorder, such as inpatient hospital clients [24]. It is important to note the role of outcome measures in epidemiological studies to track naturalistic change in non-clinical populations.

To be clinically useful, outcome measures need to be meaningful to clients and relevant to the areas in which they have treatment goals. Research with mental health service consumers shows that many measures are not particularly relevant to their situations and do not capture outcomes that are personally meaningful [25]. Determining an outcome measure that is applicable in both clinical work and service evaluation is challenging [26]. Mental health is a broad construct that comprises a number of different measurement domains [27]. These include measures that cover recovery, cognitive performance and emotional experience, ability to undertake daily activities and maintain interpersonal relationships consistent with development stage, and general life satisfaction and wellbeing [1, 28, 29]. Each domain has been recognised as providing a meaningful aspect of a client's mental health status, but may vary in value for clinical use, service evaluation and epidemiological studies [27].

There is a long history of outcome measures for adult mental health services and for child and adolescent services, including both community-based and inpatient settings. In Australia, a comprehensive report on outcome measurement in community settings identified 136 measures, of which 31 were deemed most appropriate and being relevant for children and adolescents, adults or older persons [29]. The measures incorporate both client and clinician reporters, and parent reporter measures were available for children and adolescents [22]. Historically, outcome measures have either been targeted towards children and adolescents or adults, reflecting the traditional demarcations within the mental health care system [30]. For example, the Health of the Nation Outcome Scales (HoNOS) has two versions, one for adults aged 18 to 64 years and a child and adolescent 
version (HoNOSCA) for those aged under 18 years [31]. Outcome measures specific to the youth transition period of adolescence and young adulthood are urgently needed due to recent changes in mental health service delivery specifically targeting this age range [32].

Reorienting mental health services to focus on young people is supported by understanding that they have the highest burden of mental illness across the lifespan, comprising $55 \%$ of the burden of illness for the 15 to 24 year old age group [33]. At least one in four young people aged 12 to 24 years experiences a mental health problem in any given year [34]. Research indicates that $75 \%$ of people suffering from a psychiatric disorder in adulthood experience onset by the age of 24 [35]. Of particular concern, however, young people are least likely to access support from mental health care organisations [32]. A systematic review of barriers and facilitators to mental health help-seeking in young people from qualitative studies identified the major barriers as problems recognising symptoms, a preference for selfreliance, and perceived stigma and embarrassment [36]. There is also a pervasive belief among young people that seeking help does not help [37]. Consequently, ways to ensure mental health support is effective, and perceived to be so, are essential to engage young people in services [38], and this requires being able to demonstrate meaningful outcomes from young people's mental health service use [39].

Due to increased vulnerability to mental disorder during adolescence and early adulthood, the transition from child and adolescent to adult mental health services at the age of 18 years is extremely disruptive to effective mental health care; it undermines continuity of care at the time when this needs to be strongest [40]. Early intervention youth mental health initiatives are strongly promoted in Australia [41] and gaining momentum in many other countries [42]. Youth-focused service innovations focus on the importance of factors such as youth participation, shared decision making, and easy early access. This has led to the development of tools and supports aimed at engaging young people, such as age appropriate psychosocial and mental health assessments [43]. New methods of delivering mental health interventions to young people have also emerged, which include online and smart phone applications of counselling, self-help, assessment, and support groups [44].

Consequently, appropriate outcome measures are now required that are appropriate to young people's developmental, social and emotional stages $[45,46]$. The current study comprised a systematic review to identify appropriate mental health outcome measures for young people aged 12 to 25 years. Specifically, the review aimed to identify outcome measures that could be used for a broad range of mental health presentations and assessed mental health through global measures of cognition and emotion, functioning, quality of life and multidimensional factors (rather than focussed on specific diagnostic symptoms). The review aimed to explore how outcome measures have been used to track change, in what populations and settings they have been used, and whether they have been used as a feedback monitoring system to clinicians.

\section{Methods}

\section{Search strategy}

The search was conducted using the MEDLINE and PsychINFO databases, covering studies published since the inception of each database until the $9^{\text {th }}$ June 2014. The search terms comprised four categories: young people, measures, mental health and change (see Table 1). These were combined using 'and' statements and searches were performed on article titles, abstracts and subjects. Additional studies were identified through hand searching the references of relevant studies and reviews. The search methodology and reported findings comply with the relevant sections of the Preferred Reporting Items for Systematic Reviews and Meta-Analyses (PRISMA) statement [47]. See Additional file 1 for PRISMA checklist.

\section{Eligibility criteria}

The eligibility criteria included articles reporting global measures of mental health, used with a range of mental health populations for young people aged 12 to 25 years, and measuring change over time. Case studies, reviews, single study specific outcome measures and studies including participants with other medical conditions were excluded. To be included, studies had to:

- be written in English;

- include participants with a mean age in the range of 12 to 25 years;

- describe an outcome measure used as a general measure of mental health, including measures of

Table 1 Search terms

\begin{tabular}{ll}
\hline Categories & Words \& phrases \\
\hline Young person & Young, youth*, adolescen* \\
Measures & Measure, assessment, rating, scale, \\
& screen, questionnaire, checklist, tool \\
Mental health & Mental health, mental illness, mental \\
& disorder, emotional problems, top \\
& problems, psychological adjustment, \\
psychological distress, psychiatric \\
disorder, well-being, global functioning, \\
quality of life \\
Change & Change, improve*, progress \\
\hline
\end{tabular}

*Is a wildcard character that may be used in place of any number of characters in a search word 
emotion and cognition, functioning, quality of life and multidimensional mental health;

- report outcome measures tracking change over at least two measurement time points; and

- be applicable to a general mental health population or used with a variety of specific mental health populations (rather than be unique to a particular mental disorder or condition).

Additionally, the criteria excluded studies:

- of only adult or child participants;

- that were case studies or reviews;

- where participants had conditions related to physical health, developmental delays, neurological impairments, intellectual disabilities, learning disorders, situational stress/trauma and substance or alcohol dependence; and

- which had an outcome measure that was single study specific.

\section{Data extraction}

Following the database search, duplicates were firstly removed. Titles and abstracts were then screened and irrelevant studies removed. Full text articles of studies identified as possibly relevant for inclusion were then obtained and both authors inspected these against the eligibility criteria for inclusion. The database search was extensive, but authors of the published articles were not contacted to obtain further information to that published. Additional searching by name of each outcome measure identified in the review was not conducted as the aim was to identify outcome measures that met the eligibility criteria rather than identify every published article on the identified measures. Figure 1 shows the PRISMA flow diagram for study inclusion.

Relevant information from each article was entered into a spreadsheet that included: age, gender, ethnicity, socioeconomic status, country, diagnosis, sample size, research design, setting, time of follow-up, reporter, measure change magnitude, and use in feedback monitoring systems. The articles were then sorted into groups by the outcome measure(s) identified in the article. If more than one eligible measure was reported, the article was included under each relevant outcome measure group. Lastly, the outcome measures were categorised according to the major domains of cognition and emotion, functioning, quality of life or multidimensional.

\section{Results}

\section{Search results}

The search strategy identified 184 published articles covering 29 different outcome measures, with many articles

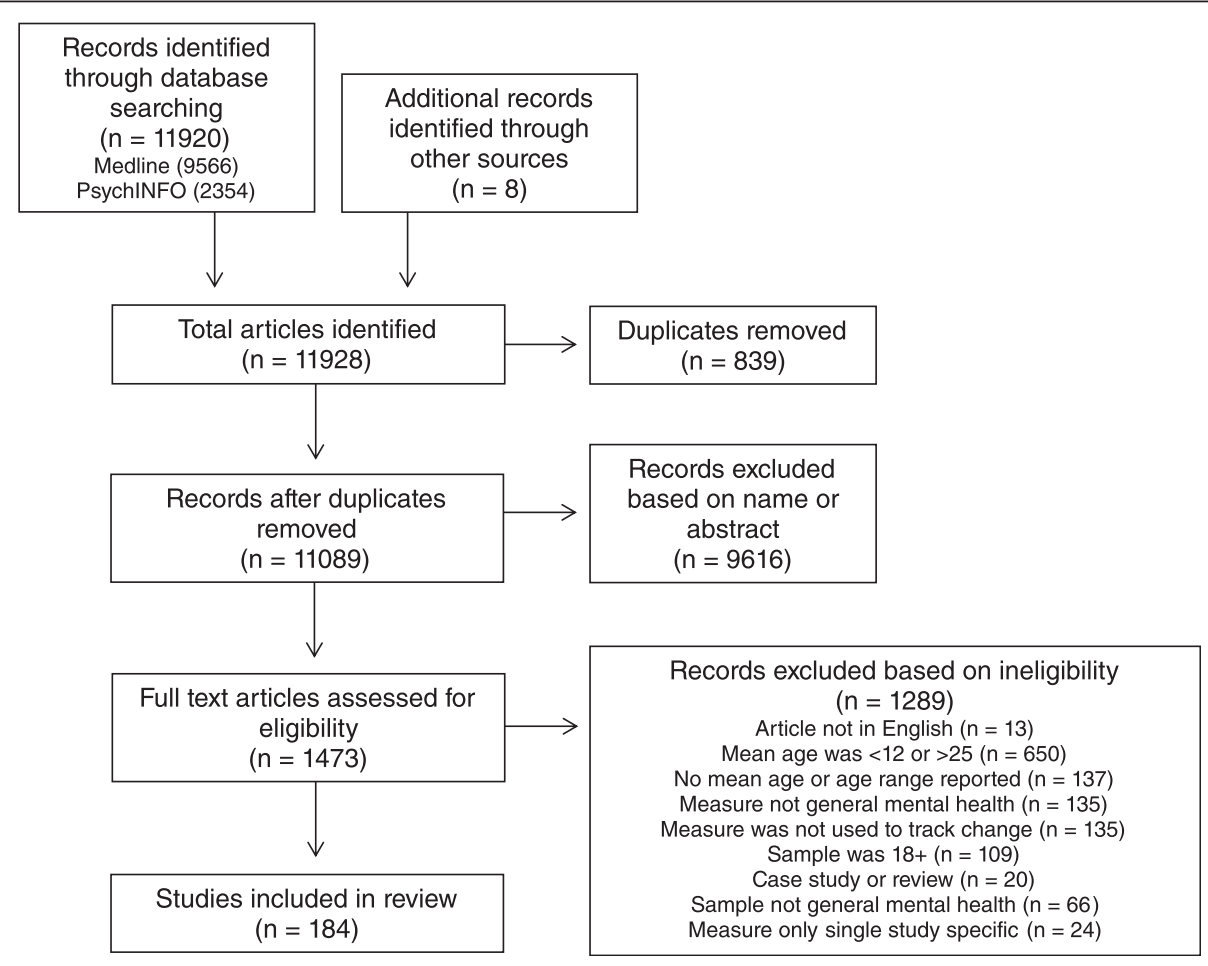

Fig. 1 PRISMA flow diagram 
identifying more than one measure. The key characteristics of each article by type of measure are summarised in Additional file 2. The outcomes comprised eight measures of cognition and emotion, nine of functioning, six that were quality of life, and six multidimensional mental health measures. The GAF, a measure of functioning, was the most commonly referenced measure overall. The most referenced measure of cognition and emotion was the CBCL; for quality of life, it was the SF-36; and the most referenced multidimensional measure was the HoNOSCA.

\section{Age range}

Figures 2, 3, 4 and 5 show the age range and mean age for each measure in each article. Of the 29 outcome measures, 22 were used in at least one study with a sample that ranged across the age 18 child/adult demarcation point. However, only 11 of these measures were used in samples that had mean ages in both the 12 to 17 and 18 to 25 year groups. These included the BPRS, GHQ-12, K10, SCL-90-R, YSR, CGAS, CGI-S, GAF, SOFAS, SF-36, and WHOQOL-BREF. The YSR and CGAS were used predominately in the under 18 year

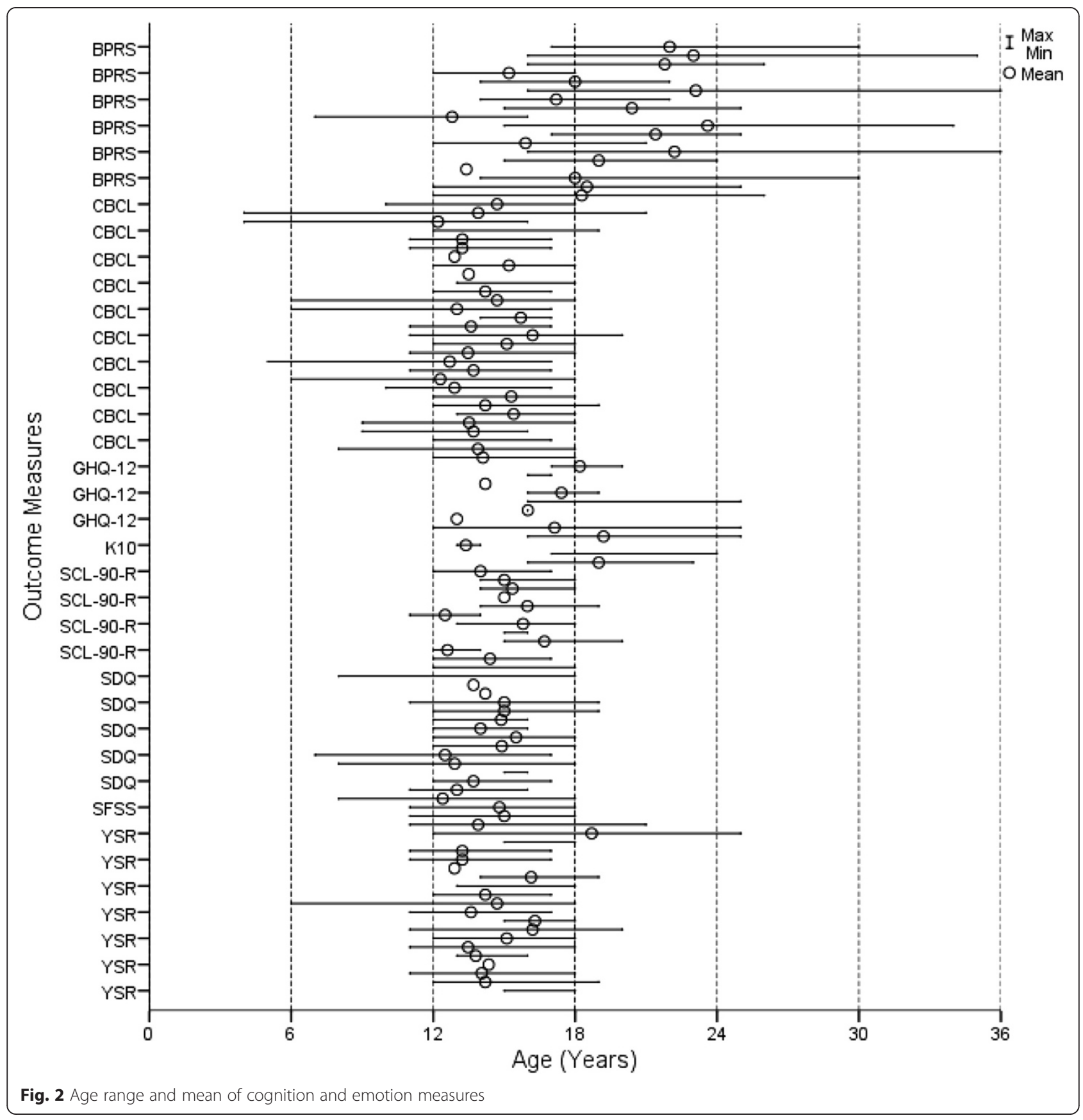




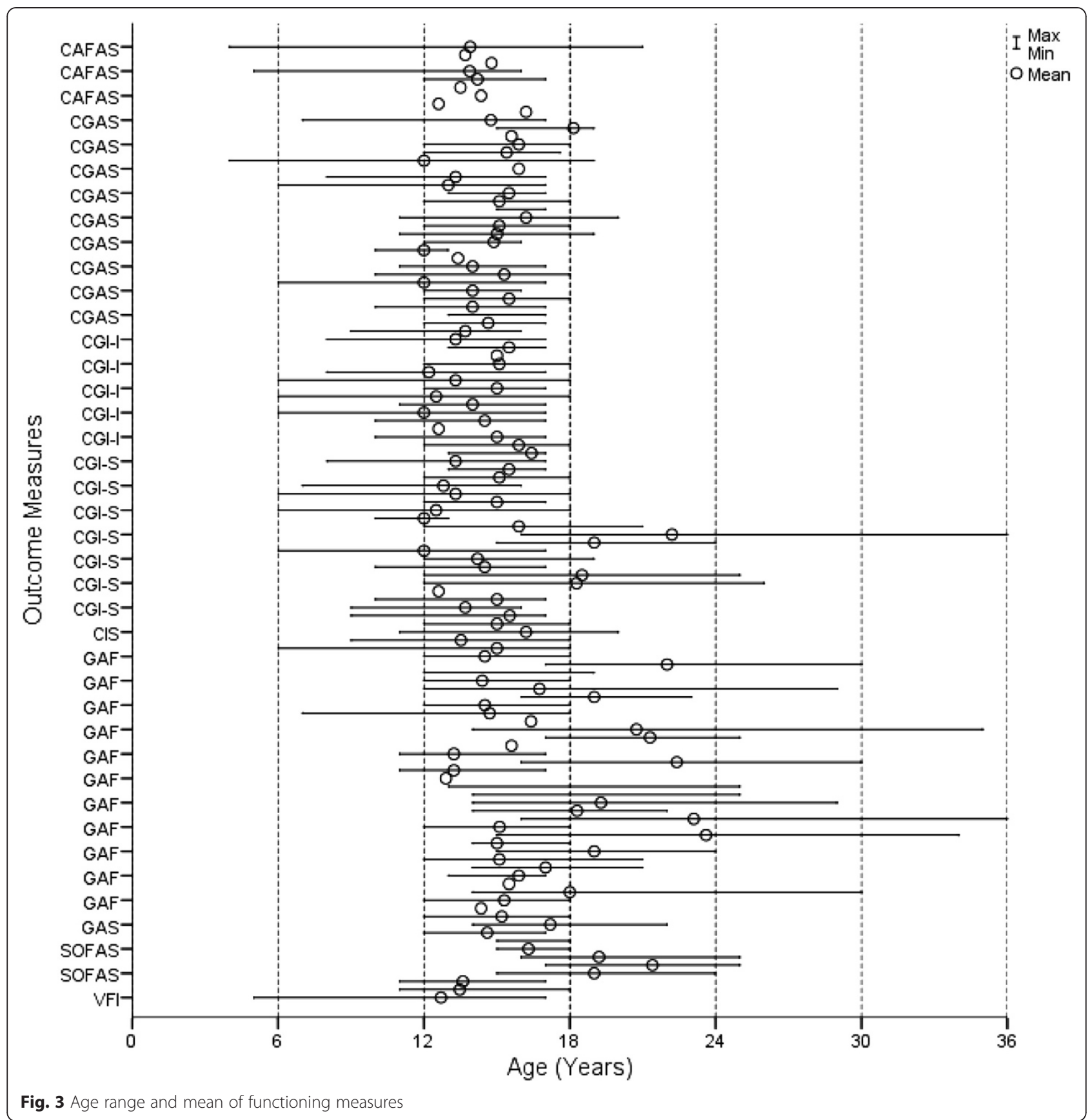

age range. It is important to note that none of the multidimensional measures were used in samples with mean ages both above and below 18 years. There were three measures used with young people below 18 years that had an adult countermeasure used at follow-up: the YSR (YASR), CGAS (GAS), and HoNOSCA (HoNOS).

Eight measures were used across the whole 12 to 25 year age range, comprising the BPRS, GHQ-12, K10, YSR, CGI-S, GAF, SF-36 and WHOQOL-BREF. The BPRS was predominately used with samples diagnosed with psychosis and schizophrenia. The YSR was slightly modified in one article, with the term 'kids' changed to 'young people', so that it could be used across the broader 12 to 25 year age group, rather than just with those aged under 18 years. The GHQ12 was only used in non-clinical samples, and mainly over longer time periods tracking naturalistic change. Consequently, there were only five measures deemed to be suitable for use across the whole 12 to 25 year age range and applicable to a variety of clinical and research settings and population groups: K10, CGI-S, GAF, SF-36 and WHOQOL-BREF. 


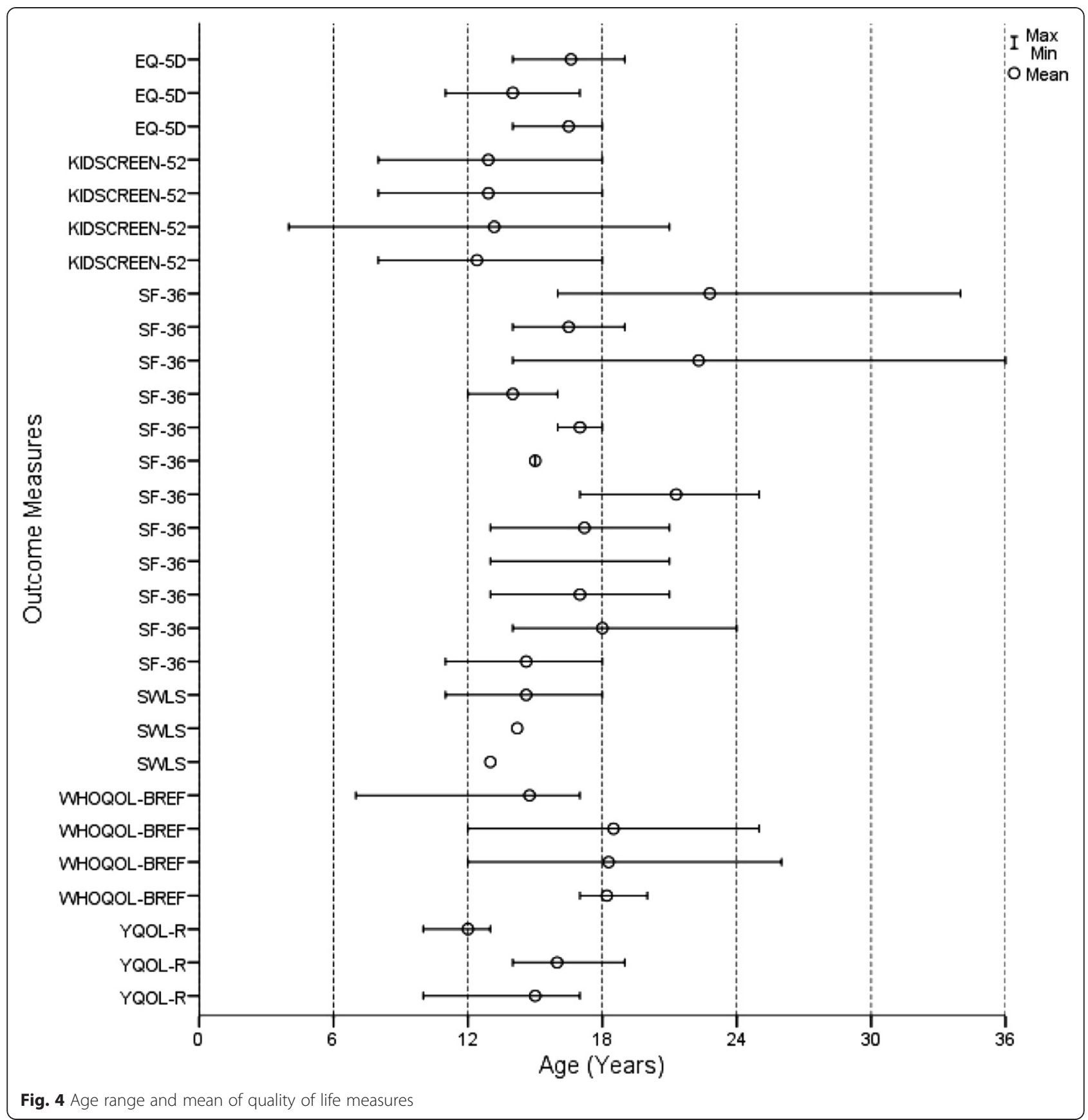

\section{Outcome measure reporter}

Outcome measures can be reported by the client (self-report), parents/carers or clinician. The review identified 13 of the 29 measures as having more than one reporter. Eight measures were self-report by the young person, which were the GHQ-12, K10, YSR, YP CORE, and all quality of life measures except the KIDSCREEN-52 and WHOQOL-BREF. Eight measures were clinician reported, comprising the HoNOS and most measures of functioning. All articles that referenced the SOFAS did not note the reporter, but this measure is clinician assessed.

Outcome measures with options for all three reporters were the SDQ, SFSS, CGI-I, and Ohio Scales. Only one of the 13 articles for the CGI-I used all three reporters, and this study aimed to explore differences between reporter types. The CBCL was the only measure with a teacher report in one article. This measure also has parent and clinician reporter versions, and a self-report version, the YSR, in the 


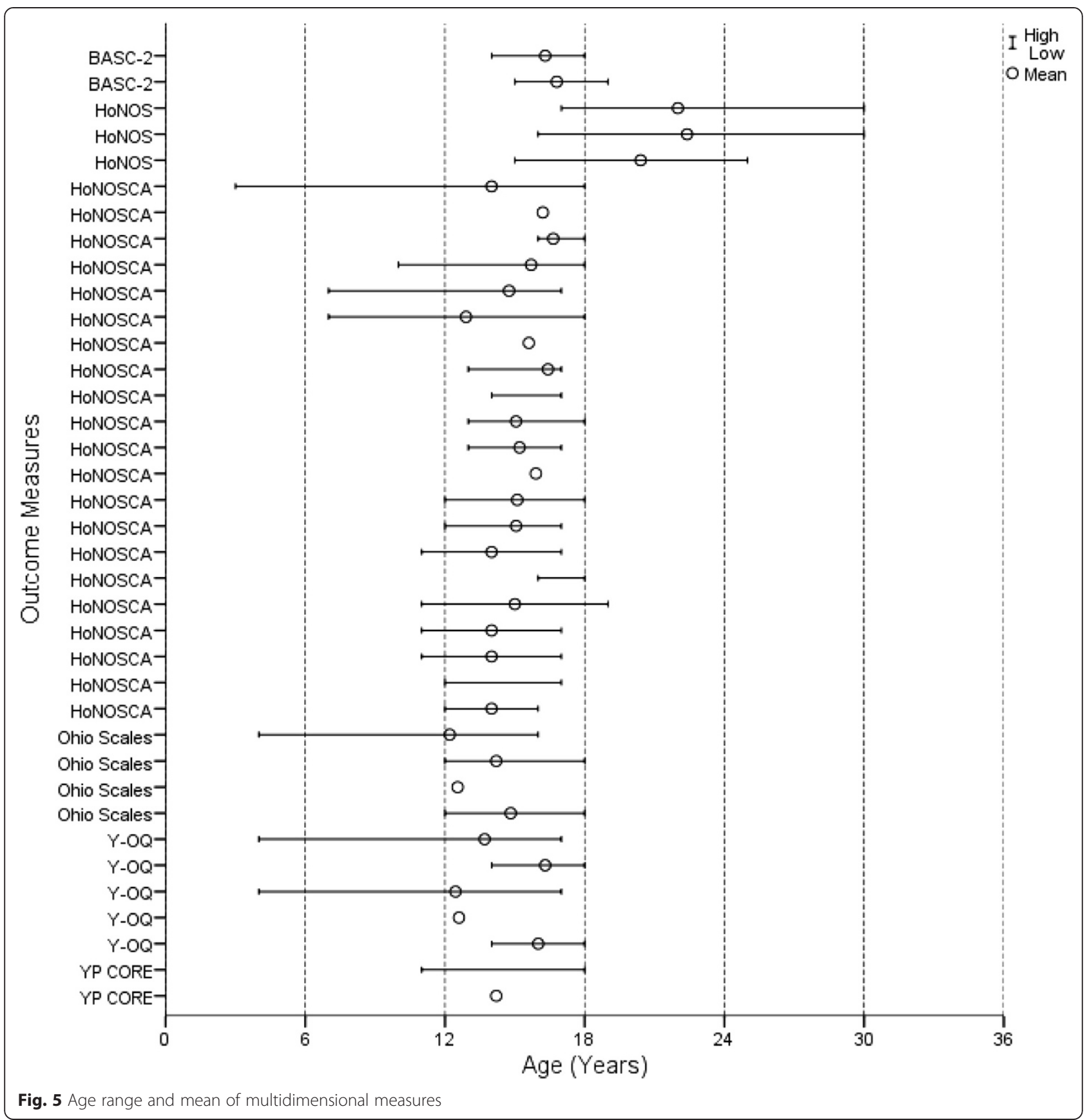

same family of measures and used in a number of the same studies. The CBCL and YSR were kept distinct, however, due to the different age ranges they target.

\section{Population groups}

Out of the 29 outcomes measures, two were used specifically in non-clinical, community-based samples: the GHQ-12 and SWLS. The remaining 27 measures were used with various clinical participant samples, and 10 measures were used in both clinical and non-clinical samples: the CBCL, K10, SDQ, SCL-90-R, YSR,
KIDSCREEN-52, SF-36, WHOQOL-BREF, BASC-2, and Y-OQ. It is important to note that all functioning measures and multidimensional measures, except the BASC2 and $\mathrm{Y}-\mathrm{OQ}$, were used only in clinical samples.

\section{Intervention types}

All outcome measures were used in at least one trial or treatment interventions. Many also explored naturalistic change over time in the absence of an intervention, including the CBCL, GHQ-12, K10, SCL-90-R, YSR, KIDSCREEN-52, SF-36, SWLS, and WHOQOL-BREF. 
The GHQ-12, KIDSCREEN-52, and SWLS were predominately used to measure naturalistic change. No measures of functioning or multidimensional mental health were used to examine naturalistic change.

\section{Change magnitude}

The review determined whether the outcome measures were used to assess change using tests of significance, effect size, reliable change and clinical significance. All but one outcome measure (SWLS) reported change magnitude over time. There were 28 measures that reported tests of significance and 17 included effects sizes. Outcome measures showing small to medium effect sizes included the BPRS, CBCL, K10, SCL-90-R, SFSS, YSR, KIDSCREEN-52, SF-36 and YP CORE. Measures showing medium to large effect sizes included the SDQ, CAFAS, CGAS, CGI-S, GAF, EQ-5D, YQOL-R and HoNOSCA. Effect sizes of small, medium and large were based on Cohen's d of 0.2, 0.5, and 0.8, respectively.

Of the five measures identified suitable for use with the whole 12 to 25 year range, the K10, CGI-S, GAF and SF-36 reported effect sizes. The K10 was used in one study involving 36 non-clinical participants comparing two online coping programs and a control over nine weeks. There was a significant main effect over time for all three groups, with a small effect size [48]. The CGI-S was used with 20 participants for treatment of anxiety, showing a large effect size over 14 weeks of treatment [49]. A study used the GAF with 74 psychiatric outpatient participants with a range of disorders being treated with a Mindfulness-Based Stress Reduction (MBSR) program compared to Treatment as Usual (TAU). After post treatment (8 weeks) and follow-up (3 months) a large effect size was evident for the MBSR group compared to a small decline in the TAU group [50]. Lastly, the SF-36 was used with 63 participants being treated for first-episode mania, demonstrating small effect sizes on both mental and physical component scores after 6, 12 and 18 months [51].

Only seven of the measures were analysed using a reliable change index, which included the SDQ, SCL-90-R, YSR, CGAS, GAF, Ohio scales, and Y-OQ. The SDQ, SCL-90-R, and CGAS were used in randomised trials which showed reliable change index cut-off comparisons between intervention and control groups. The SDQ, used in a randomised trial of Acceptance and Commitment Therapy (ACT) compared to TAU, showed a reliable improvement for $26 \%$ compared to $0 \%$ at post treatment, respectively [52]. In a randomised trial reporting reliable change using the SCL-90-R, MBSR showed $59 \%$ of participants with no change and $41 \%$ improved, while TAU showed $10 \%$ worsened, $62 \%$ had no change and $27 \%$ improved [50]. The CGAS was used in a study of female Apache American Indians with depression, to measure outcomes for a cognitive-behaviour based program versus an education support program. Differences in reliable change between the two interventions were reported at post intervention ( 8 weeks), 12 weeks, 20 weeks and 32 weeks [53].

Five outcome measures used tests of both clinical significance and reliable change; namely, the SCL-90-R, YSR, GAF, Ohio Scales, and Y-OQ. The GAF was used in a young adults' counselling centre with 78 Swedes aged 16 to 23 years with a range of mental health disorders. A reliable improvement was calculated to be an increase of at least 10 points on the GAF. At post treatment, with mean length of treatment being 11 months, $52 \%$ of participants showed reliable improvement while $48 \%$ showed no change. Additionally, $31 \%$ demonstrated clinically significant improvement [54]. A study using the Y-OQ in a school-based mental health treatment program reported both reliable change and clinical significance to conclude that $45 \%$ of clients had "recovered" by meeting both criteria [55].

\section{Follow-up time frame}

The systematic review extracted follow-up time frames for the outcome measure studies, and categorised these as: short-term (0-6 months), medium-term (over 6 months-1 year), and long-term (over 1 year). Many measures were used across all three time frames. Measures used only in a short-term time frame included the SFSS, BASC-2, and Ohio Scales. The CGI-I, CGI-S, YQOL-R, and Y-OQ were primarily used in short-term time frames but did have some variation. Two measures primarily used in a long-term time frame were the KIDSCREEN-52 and GHQ-12. A small number of studies reported routine use of outcome measures, whereby the same measure was used at multiple time points: SDQ, SFSS, and Y-OQ.

\section{Sample demographics}

The outcome measures were all used with a range of sample demographics, according to gender, ethnicity and socioeconomic status. All 29 outcome measures were applied in equivalent ways for males and females; only one study using the K10 identified a participant that was transgender.

The majority of studies did not report ethnicity and, for those that did, there was little consistency. There were five measures that only reported primarily Caucasian samples, but no further information on what this broad category comprised, which were the VFI, SFSS, EQ-5D, BASC-2, and Ohio Scales.

In most studies, the socioeconomic status of the sample was not reported. Outcome measures that reported being used in a lower socioeconomic sample included 
the CBCL, GHQ-12, SDQ, YSR, CGAS, CIS, GAF, SOFAS, VFI, and SWLS.

\section{Feedback systems}

The review identified three outcome measures used routinely, however only two of these measures were used as part of a feedback monitoring system, the SDQ and SFSS. In each case, these measures were used repeatedly to provide routine feedback to the clinician on the young person's outcomes. No functioning, quality of life or multidimensional measures were used as a feedback monitoring system.

The SDQ was specifically adapted in one study to be able to be used routinely in a feedback system. This session by session measure ( $\mathrm{SxS}$ ) was used to examine treatment effects using the feedback monitoring system during TAU over a year. Participants were recruited from Child and Adolescent Mental Health Services outpatient clinics, aged 11 to 19 years with a range of mental health disorders. The young clients and parents reported the SxS measure, which was fed back to clinicians and discussed with the young client. Results showed statistically significant changes after a year on the CGAS and young person reported SxS, however, no statistically significant changes in the HoNOSCA and parent reported SxS [56].

The SFSS was used in a randomised cluster controlled trial comparing weekly feedback versus no feedback monitoring system with young people being treated for a range of mental health disorders. Participants were recruited through a private health organisation, were aged 11 to 18 years and participated in the study for a mean time of 16.5 weeks. The SFSS used young person, parent and clinician reporters. Client participants with clinicians who received feedback on the SFSS improved faster than those with no feedback. Feedback effect sizes were small, being $0.18,0.24$, and 0.27 for reports from young people, clinicians, and parents, respectively. There were stronger effects when clinicians viewed multiple reporter sources; that is, from young persons, parents and clinician [12].

\section{Discussion}

This systematic review identified 29 mental health outcome measures, reported in 184 articles examining change in mental health status for young people aged from 12 to 25 years. It is the first review to examine outcome measures specifically across this age range. Prior reviews have reflected the traditional mental health service system demarcation by focussing on outcome measures used with either children and adolescents or with adults $[22,29]$. The focus of the review was on general mental health outcome measures, rather than disorderspecific symptom measures, consistent with recent research highlighting the need to measure outcomes across comorbid conditions, changing presenting problems, and different client types and settings [22, 29].

\section{Age range appropriate measures}

There were eight outcome measures identified as being used across the whole 12 to 25 year age range. These were the BPRS, GHQ-12, K10, YSR, CGI-S, GAF, SF-36 and WHOQOL-BREF, but none are developed specifically for this target age range. Three measures are considered to be less appropriate for general youth mental health, namely: the BPRS, because it is used primarily with psychosis; the YSR, as it was specifically designed for clients under the age of 18 years; and the GHQ-12, which is mainly used with non-clinical samples to track naturalistic change. This leaves five measures deemed suitable for use across the whole 12 to 25 year age range and applicable to a variety of clinical and research settings and population groups: K10, CGI-S, GAF, SF-36 and WHOQOL-BREF. A discussion of their strengths and weaknesses follows.

The K10 was developed by Kessler and colleagues as a measure of non-specific psychological distress. It is a 10item self-report measure which asks clients about symptoms of anxiety and depression in the past four weeks. The K10 has been widely used as a measure of mental health status in population surveys as well as an outcome measure in primary care settings. It demonstrates strong validity, excellent reliability and has been shown to be sensitive to change [29]. No studies have examined the feasibility of the K10 as a routine outcome measure; however, it has been noted as easy to use, brief and is one of the key outcome measures for the Better Outcomes in Mental Health Care Initiative in Australia [29]. In the current review, the K10 was shown to be used with clinical and non-clinical samples, tracking both treatment effects and naturalistic change. Change in the K10 was reported mainly with tests of statistical significance and a small effect size was demonstrated in one study.

The CGI-S is a brief clinician-rated global measure of current severity of the client's symptoms and functioning. The CGI-S is one-item asking the clinician, in their clinical experience, how mentally ill the client has been over the past week from "normal" to "extremely ill" [57]. The CGI-S has been shown to be sensitive to change, showing similar change to the HoNOS. It has been identified as suitable for routine use due to its brevity and ease of administration [58]. However, there are questions about its validity and reliability and efforts have been made to improve its psychometric properties [59]. In the current review, the CGI-S was used only with clinical samples, and change was reported using statistical significance and effect size, revealing large statistical effects. 
The GAF is a clinician-rated scale giving a measure of overall psychiatric disturbance integrating three dimensions of functioning: psychological, social and occupational. It is a single-item measure on a 100-point scale divided into 10-point intervals [60]. It has shown good construct and concurrent validity, but questions have been raised over its content validity. Inter-rater reliability can be low, particularly in routine clinical use [29]. It is sensitive to change when correlated with change in the Positive and Negative Syndrome Scale (PANSS) [61]. The GAF is brief, easy to use and reliability can be increased with minimal training, which makes it more acceptable in routine clinical settings [29]. In the current review, the GAF was the most frequently referenced measure, was used in only clinical samples, and showed large effect sizes and both reliable and clinically significant change. The GAF was included in the revised third and fourth editions of the Diagnostic and Statistical Manual (DSM), but removed from Version 5 in favour of the World Health Organization Disability Assessment Schedule 2.0. The DSM-5 Task Force decided that the GAF was not an adequate assessment of psychiatric functional impairment due to its lack of conceptual clarity, the need for separate assessment of severity and disability, questionable psychometrics in routine practice, and the need for specific training for proper routine clinical use [62].

The SF-36 is a multipurpose, self-report, short-form health survey containing 36 items grouped under eight scales: physical functioning, role limitation due to physical functioning, bodily pain, general health, vitality, social functioning, role limitation due to emotional problems and mental health. The eight scales can be summed into physical and mental health summary scores. The SF-36 has been used with a range of mental disorders and physical diseases, and a variety of treatments. It has been shown to be valid, reliable, sensitive to change, brief and easy to use [29]. In the current review, it was the most referenced measure of quality of life, when including its shorter 12 -item version. The SF36 was used in both clinical and non-clinical settings, over short to long-term time frames, and showed small to medium effect sizes.

The Australian WHOQOL-BREF comprises 26 items measuring broad domains of physical health, psychological health, social relationships and environment over the last two weeks. It has good validity, reliability and sensitivity to change, however, has been suggested to be more appropriate for use at a population level [29]. In the current review, it was used primarily with clinical samples over short time frames, although one study used a larger non-clinical sample tracking naturalistic change. The WHOQOL-BREF has both young people and clinician reporters, however, self- report is recommended if the client has sufficient ability to complete the measure.

These five outcome measures were used effectively in studies of samples spanning the 12 to 25 year age range, even though they were originally developed for use with adults. None of these measures has been tested specifically for its clinical utility or psychometric properties for the youth age range. The current review did not identify any outcome measures developed specifically for the adolescent and young adult demographic. While these five measures seem promising, further tests of psychometrics and clinical utility are needed.

Despite the lack of targeted measures, there were 22 out of 29 outcome measures identified in the review that were used in at least one study with a sample that ranged across the 18 years of age mental health service system demarcation point. These included measures that were originally developed to be used with young people only up to the age of 18 years, such as the CBCL, YSR, and KIDSCREEN-52 [63-65]. This reveals the need for specifically developed and targeted measures for young people. There are major developmental changes that occur for young people from the ages of 12 years, around the time of the onset of puberty, to 25 years, which is well into adulthood [66]. It is highly likely that useful measures for this age range would need some clearly defined flexibility to accommodate developmental changes, particularly in areas of psychosocial functioning such as intimate relationships, education and work.

\section{Type of reporter}

Outcome measures can be self-report, clinician report or reported by relevant others (such as parents or teachers), and these different perspectives are all important for treatment [46]. In particular, self-report measures are essential for youth, to recognise their growing maturity and independence and engage them in their own treatment progress.

The place of parent reports may need further consideration, however, the current review identified very little use of parent reporters across the 12-25 age range, and only for children and adolescents [22]. New models of youth-focused care recognise the critical role of family, and parent reports may be relevant for clients up to 25 years of age [42], by providing another source of insight, particularly around changes in behavioural difficulties [67]. Careful attention would, however, need to be given to consent and confidentiality issues $[66,68]$.

\section{Tracking change}

All the outcome measures identified in this systematic review were used to track change over time. There were eight measures used primarily within a six month period, suggesting they might be more sensitive to 
change in a relatively short time frame. In contrast, the KIDSCREEN-52 and GHQ-12 were used predominately in longitudinal population studies. Only three out of 29 outcome measures reported being used routinely used at multiple time points: SDQ, SFSS, and Y-OQ. Routine use of outcome measures is a necessity when used as a feedback monitoring system, and this was demonstrated in studies using the SDQ and SFSS.

Only seven outcome measures were used to report reliable change, and only five of these also reported clinically significant change. This is concerning as studies have shown that reliable and clinically significant are more clinically meaningful change measures for mental health research [13]. These methods were designed to account for measurement error and clinical thresholds, requiring change to be statistically reliable and demonstrate movement from a dysfunctional to the functional population distribution [15]. Using these criteria, individuals can be classified into the outcome categories of recovered, improved, unchanged, or deteriorated, which are meaningful and interpretable categories [16]. However, it should be noted, that calculations of reliable change and clinical significance produce more conservative change results than other approaches $[16,69]$. Further, in an early intervention context, clinical significance may not be appropriate as most clients may not present in the dysfunctional range to start with. In these contexts, clinical deterioration should be monitored, however, to determine whether clients change from the functional to the dysfunctional distribution, indicating need for higher levels of intervention. More research is needed in this area to determine optimal change indices for youth outcome measures.

\section{Routine feedback}

There has been an increase in demand for outcome measures to be used as a feedback monitoring system for clinicians [8]. Very few outcome measures were identified in the current systematic review that were used in this way, and these were designed for children and adolescents under 18 years [70]. The SDQ used young person and parent reporters and this information was fed back to clinicians to discuss with the young person. Treatment as usual with SDQ feedback showed statistically significant change on the CGAS post treatment, however, the study did not have a comparison group so it was unknown whether the change was due to the feedback, treatment as usual or the combination of both [56]. The SFSS study used young person, parent and clinician reporters and this information was fed back to clinician, but the study did not specify if this information was fed back to the young person. Feedback was found to improve client change, and this was heightened when feedback came from multiple sources [12]. Multiple feedback sources can provide different change perspectives of value to the clinician and young person client [46].

Of special note, the study using the SDQ within a feedback monitoring system showed that the measure had to be modified to be used in this way [56]. This suggests the possibility of other measures being modified or adapted to be used routinely. There are, however, several barriers to routine feedback, which may account for the small number of measures identified here $[2,71]$. These include constraints around time, resources and training needed, and perceived lack of clinical utility [72]. There are likely to be additional barriers for young people as clients, as they are a unique client group with higher dropout rates, are often referred by parents or teachers rather than being self-referred, and have different goals for therapy and therapeutic expectations compared with adults [20].

\section{Limitations}

A thorough search strategy was employed in this systematic review and it identified a large number of outcome measures and studies, but it is possible that relevant measures were missed. Notably, article authors were not contacted for additional information and the methodology excluded articles that were not written in English, meaning measures used specifically in other cultures were excluded. The eligibility criteria also excluded articles pertaining to participants with other health conditions, including substance use and situational stressors. This was done partly to make the review more manageable, but may have excluded relevant measures. Only two databases were used in the search strategy, MEDLINE and PsychINFO, although these are the most commonly used in systematic reviews of mental health outcome measures [22, 45, 73]. Together, the databased yielded an initial 11920 articles, which was filtered to a comprehensive 184 studies, identifying 29 outcome measures. Nevertheless, some measures, especially those not often used for research purposes and primarily used in clinical practice, may have been missed.

In particular, some popular outcome measures were not identified via the final criteria, including the Depression Anxiety Stress Scale (DASS) and the Outcome Rating Scale (ORS). The DASS is a self-report measure which comes in a 21 or 42 -item version [74]. It is commonly used as individual scores for depression, anxiety and stress and, therefore, was excluded as measuring specific mental health conditions. The ORS is an outcome measure developed as a brief alternative to the Outcome Questionnaire 45.2 (OQ-45.2) [75]. The Y-OQ, which was included in this review, also comes from the same family of measures. There is a growing body of research around the ORS, particularly regarding its use as a feedback 
monitoring system for clinicians [76]. However, in this review, it was excluded as it was unique to only one study with young people aged 12 to 25 years [77].

\section{Conclusions}

Mental health outcome measures are essential for quality assurance and monitoring the effectiveness of services, and for tracking longitudinal health trends across time $[5,6]$. Although this review identified a large number of measures used with young people aged 12 to 25 years, only eight were used across this whole age range, each with strengths and weaknesses. Overall, the review found no measures designed specifically for young people. There is a growing push for outcome measures to be routinely used as feedback monitoring systems, and to determine clinically meaningful change $[7,20]$. Only two measures were identified here as being used in this way and this is an area of particular research need for youth mental health because of the potential for such an approach to benefit clients [12]. Future research should focus on development of mental health outcome measures designed specifically for young people aged 12 to 25 years to accompany changes in mental health services that target this age range. The measures should be sensitive to reliable and possibly clinically significant change that is meaningful to young people, and also suitable for routine use as feedback to clinicians and young people themselves. This will provide services with age-appropriate measures with better clinical utility and comparative usefulness to drive delivery of the better mental health outcomes for young people, who have such a heightened need for early and effective mental health care.

\section{Additional files}

Additional file 1: PRISMA checklist. (PDF $192 \mathrm{~kb}$ )

Additional file 2: Mental health outcome measures used with young people 12 to 25 years [78-248]. (XLSX $46 \mathrm{~kb}$ )

\section{Abbreviations}

ACT: Acceptance and Commitment Therapy; ASR: Adult Self-Report; BASC2: Behavioural Assessment System for Children-2; BPRS: Brief Psychiatric Rating Scale; CAFAS: Child and Adolescent Functional Assessment Scale; CBCL: Child Behaviour Check List; CGAS: Children's Global Assessment Scale; CGI-I: Clinical Global Impressions Scales-Improvement scales; CGI-S: Clinical Global Impressions Scales-Severity of IIIness; CIS: Columbia Impairment Scale; DASS: Depression Anxiety Stress Scale; DSM: Diagnostic and Statistical Manual; EQ-5D: EuroQol; GAF: Global Assessment of Functioning; GAS: Global Assessment Scale; GHQ-12: General Health Questionnaire-12; HoNOS: Health of the Nation Outcome Scale; HoNOSCA: Health of the Nation Outcome Scales for Children and Adolescents; K10: Kessler Psychological Distress Scale; MBSR: Mindfulness-Based Stress Reduction; OQ-45.2: Outcome Questionnaire 45.2; ORS: Outcome Rating Scale; PANSS: Positive and Negative Syndrome Scale; PRISMA: Preferred Reporting Items for Systematic Reviews and Meta-Analyses; SCL-90-R: Symptom Checklist 90 Revised; SDQ: Strengths and Difficulties Questionnaire; SF-12: Medical Outcomes Study (MOS) 12-item Short Form Health Survey; SF-36: Medical Outcomes Study
(MOS) 36-item Short Form Health Survey; SFSS: Symptom and Functioning Severity Scale; SOFAS: Social and Occupational Functioning Assessment Scale; SWLS: Satisfaction with Life Scale; SxS: Session by session measure; TAU: Treatment as Usual; VFI,: Vanderbilt Functioning Index; WHOQOL-BREF: World Health Organisation Quality of Life InstrumentBrief; Y-OQ: Youth Outcome Questionnaire; YASR: Young Adult Self-Report; YOQ-30: Youth Outcome Questionnaire-30; YP CORE: Young Persons Clinical Outcomes for Routine Evaluation questionnaire; YQOL-R: Youth Quality of Life Instrument-Research Version; YSR: Youth Self-Report.

\section{Competing interests}

The authors declare that they have no competing interests.

\section{Authors' contributions}

BK designed and undertook the systematic review and drafted the article. DJR supervised the design, reviewed the results, and revised the article. All authors read and approved the final version of the manuscript.

\section{Authors' information}

Benjamin Kwan is undertaking a PhD in Clinical Psychology in the Faculty of Health at the University of Canberra. Dr Debra J Rickwood is Professor of Psychology in the Faculty of Health at the University of Canberra and Chief Scientific Advisor to headspace The National Youth Mental Health Foundation.

\section{Acknowledgements}

None.

\section{Author details}

${ }^{1}$ Faculty of Health, University of Canberra, Kirinari Street, Bruce, ACT 2601, Australia. ${ }^{2}$ Headspace National Youth Mental Health Foundation National Office, 485 La Trobe Street, Melbourne, VIC 3000, Australia.

Received: 20 April 2015 Accepted: 27 October 2015

Published online: 14 November 2015

\section{References}

1. Slade M. What outcomes to measure in routine mental health services, and how to assess them: a systematic review. Aust N Z J Psychiatry. 2002;36(6): 743-53.

2. Batty MJ, Moldavsky M, Foroushani PS, Pass S, Marriott M, Sayal K, et al. Implementing routine outcome measures in child and adolescent mental health services: from present to future practice. Child Adolesc Mental Health. 2013;18(2):82-7. doi:10.1111/j.1475-3588.2012.00658.x.

3. Hall C, Moldavsky M, Baldwin L, Marriott M, Newell K, Taylor J, et al. The use of routine outcome measures in two child and adolescent mental health services: a completed audit cycle. BMC Psychiatry. 2013;13(1):270.

4. Brann $P$, Coleman $G$. On the meaning of change in a clinician's routine measure of outcome: HoNOSCA. Aust N Z J Psychiatry. 2010;44(12): 1097-104. doi:10.3109/00048674.2010.513037.

5. Coombs T, Stapley K, Pirkis J. The multiple uses of routine mental health outcome measures in Australia and New Zealand: experiences from the field. Australas Psychiatry. 2011;19(3):247-53. doi:10.3109/ 10398562.2011.562507

6. Happell B. The value of routine outcome measurement for consumers of mental health services: master or servant? Int J Soc Psychiatry. 2008;54(4): 317-27.

7. Bickman L. A measurement feedback system (MFS) is necessary to improve mental health outcomes. J Am Acad Child Adolesc Psychiatry. 2008;47: 1114-9.

8. Kelley SD, Bickman L. Beyond outcomes monitoring: Measurement feedback systems (MFS) in child and adolescent clinical practice. Curr Opin Psychiatry. 2009;22(4):363.

9. Carlier IVE, Meuldijk D, Van Vliet IM, Van Fenema E, Van der Wee NJA Zitman FG. Routine outcome monitoring and feedback on physical or mental health status: evidence and theory. J Eval Clin Pract. 2012;18(1): 104-10. doi:10.1111/j.1365-2753.2010.01543.x.

10. Whipple JL, Lambert MJ, Vermeersch DA, Smart DW, Nielsen SL, Hawkins EJ. Improving the effects of psychotherapy: The use of early identification of treatment and problem-solving strategies in routine practice. J Couns Psychol. 2003;50(1):59. 
11. Bearman SK, Weisz JR. Review: Comprehensive treatments for youth comorbidity - evidence-guided approaches to a complicated problem. Child and Adolescent Mental Health. 2015:n/a-n/a. doi:10.1111/camh. 12092.

12. Bickman L, Kelley SD, Breda C, de Andrade AR, Riemer M. Effects of routine feedback to clinicians on mental health outcomes of youths: results of a randomized trial. Psychiatr Serv. 2011;62(12):1423-9.

13. Liang MH. Longitudinal construct validity: establishment of clinical meaning in patient evaluative instruments. Med Care. 2000;38(9):II-84-90.

14. Wolpert M, Görzig A, Deighton J, Fugard AJB, Newman R, Ford T. Comparison of indices of clinically meaningful change in child and adolescent mental health services: difference scores, reliable change, crossing clinical thresholds and 'added value' - an exploration using parent rated scores on the SDQ. Child and Adolescent Mental Health. 2014:n/a-n/a. doi:10.1111/camh.12080.

15. Jacobson NS, Truax P. Clinical significance: a statistical approach to defining meaningful change in psychotherapy research. J Consult Clin Psychol. 1991; 59(1):12.

16. Wise EA. Methods for analyzing psychotherapy outcomes: A review of clinical significance, reliable change, and recommendations for future directions. J Pers Assess. 2004;82(1):50-9.

17. Jacobson NS, Follette WC, Revenstorf D. Psychotherapy outcome research: Methods for reporting variability and evaluating clinical significance. Behav Ther. 1984;15(4):336-52. doi:10.1016/S0005-7894(84)80002-7.

18. Eisen SV, Ranganathan G, Seal P, Spiro III A. Measuring clinically meaningful change following mental health treatment. J Behav Health Serv Res. 2007; 34(3):272-89.

19. Wyrwich KW, Bullinger M, Aaronson N, Hays RD, Patrick DL, Symonds T. Estimating clinically significant differences in quality of life outcomes. Qual Life Res. 2005;14(2):285-95.

20. Rickwood DJ, Mazzer KR, Telford NR, Parker AG, Tanti CJ, McGorry PD. Changes in psychological distress and psychosocial functioning in young people visiting headspace centres formental health problems. Med J Aust. 2015;202(10):537-42. doi:10.5694/mja14.01696.

21. Gilbody SM, House AO, Sheldon TA. Routinely administered questionnaires for depression and anxiety: systematic review. BMJ. 2001;322(7283):406-9. doi:10.1136/bmj.322.7283.406.

22. Deighton J, Croudace T, Fonagy P, Brown J, Patalay P, Wolpert M. Measuring mental health and wellbeing outcomes for children and adolescents to inform practice and policy: a review of child self-report measures. Child Adolesc Psychiatry Mental Health. 2014;8(1):14.

23. Weisz JR, Jensen-Doss A, Hawley KM. Evidence-based youth psychotherapies versus usual clinical care: a meta-analysis of direct comparisons. Am Psychol. 2006;61(7):671.

24. Dickens G. Mental health outcome measures in the age of recovery-based services. Br J Nurs. 2009;18(15):940-3.

25. Crawford MJ, Robotham D, Thana L, Patterson S, Weaver T, Barber R et al. Selecting outcome measures in mental health: the views of service users. Journal of Mental Health. 2011;20(4):336-46. doi:doi:10.3109/09638237.2011. 577114.

26. Wolpert M. Uses and Abuses of Patient Reported Outcome Measures (PROMs): Potential latrogenic Impact of PROMs Implementation and How It Can Be Mitigated. Adm Policy Ment Health. 2014;41(2):141-5. doi:10.1007/ s10488-013-0509-1.

27. Wolpert $\mathrm{M}$, Cheng $\mathrm{H}$, Deighton J. Measurement Issues: Review of four patient reported outcome measures: SDQ, RCADS, C/ORS and GBO their strengths and limitations for clinical use and service evaluation. Child Adolesc Mental Health. 2015;20(1):63-70. doi:10.1111/camh. 12065.

28. Fossey EM, Harvey CA. A conceptual review of functioning: implications for the development of consumer outcome measures. Aust N Z J Psychiatry. 2001;35(1):91-8. doi:10.1046/j.1440-1614.2001.00846.x

29. Australia AMHOaCNaCMH. National Community Managed Organisation (CMO) Outcome Measurement Project: Final Report to the Mental Health Information Strategy Standing Committee 1.1. Sydney, NSW2013.

30. Patel V, Flisher AJ, Hetrick S, McGorry P. Mental health of young people: a global public-health challenge. Lancet. 2007;369(9569): 1302-13. doi:10.1016/S0140-6736(07)60368-7.

31. Pirkis J, Burgess P, Kirk P, Dodson S, Coombs T, Williamson M. A review of the psychometric properties of the Health of the Nation Outcome Scales (HoNOS) family of measures. Health Qual Life Outcomes. 2005;3(1):76.
32. McGorry P, Bates T, Birchwood M. Designing youth mental health services for the 21st century: examples from Australia, Ireland and the UK. Br J Psychiatry Suppl. 2013;54:s30-s5. doi:10.1192/bjp.bp.112.119214.

33. Mathers C, Vos T, Stevenson C. The burden of disease and injury in Australia. Canberra: Australian Institute of Health and Welfare; 1999.

34. Slade T, Johnston A, Teesson M, Whiteford H, Burgess P, Pirkis J, et al. The Mental Health of Australians 2: Report on the 2007 National Survey of Mental Health and Wellbeing. Canberra: Department of Health and Ageing; 2009.

35. Kessler RC, Berglund P, Demler O, Jin R, Merikangas KR, Walters EE. Lifetime prevalence and age-of-onset distributions of dsm-iv disorders in the national comorbidity survey replication. Arch Gen Psychiatry. 2005;62(6): 593-602. doi:10.1001/archpsyc.62.6.593.

36. Gulliver A, Griffiths K, Christensen H. Perceived barriers and facilitators to mental health help-seeking in young people: a systematic review. BMC Psychiatry. 2010;10(1):113.

37. Rickwood D, Deane FP, Wilson CJ, Ciarrochi J. Young people's help-seeking for mental health problems. AeJAMH (Australian e-Journal for the Advancement of Mental Health). 2005;4(3):218-251. doi:10.5172/jamh.4.3.218.

38. Watsford C, Rickwood D. Young people's expectations, preferences, and experiences of therapy: Effects on clinical outcome, service use, and helpseeking intentions. Clin Psychol. 2014;18(1):43-51. doi:10.1111/cp.12034.

39. Donald IN, Rickwood DJ, Carey TA. Understanding therapeutic change in young people-A pressing research agenda. J Psychother Integr. 2014;24(4): 313-22. doi:10.1037/a0038136.

40. Singh SP, Evans N, Sireling L, Stuart H. Mind the gap: the interface between child and adult mental health services. Psychiatr Bull. 2005; 29(8):292-4. doi:10.1192/pb.29.8.292.

41. McGorry PD. The specialist youth mental health model: strengthening the weakest link in the public mental health system. Med J Australia. 2007; 187(7):S53-S6.

42. McGorry PD, Goldstone SD, Parker AG, Rickwood DJ, Hickie IB. Cultures for mental health care of young people: an Australian blueprint for reform. Lancet Psychiatry. 2014;1(7):559-68. doi:10.1016/S2215-0366(14)00082-0.

43. Bradford S, Rickwood D. Psychosocial assessments for young people: a systematic review examining acceptability, disclosure and engagement, and predictive utility. Adolesc Health Med Ther. 2012;3: 111-25. doi:10.2147/AHMT.S38442.

44. Dowling M, Rickwood D. Online counseling and therapy for mental health problems: A systematic review of individual synchronous interventions using chat. J Technol Hum Serv. 2013;31(1):1-21. doi:10.1080/15228835.2012.728508.

45. Tsang KLV, Wong PYH, Lo SK. Assessing psychosocial well-being of adolescents: A systematic review of measuring instruments. Child Care Health Dev. 2012;38(5):629-46. doi:10.1111/j.1365-2214.2011.01355.x.

46. Wolpert M, Ford T, Trustam E, Law D, Deighton J, Flannery H et al. Patientreported outcomes in child and adolescent mental health services (CAMHS): use of idiographic and standardized measures. Journal Of Mental Health (Abingdon, England). 2012;21(2):165-73. doi:10.3109/09638237.2012.664304.

47. Moher D, Liberati A, Tetzlaff J, Altman DG. Preferred Reporting Items for Systematic Reviews and Meta-Analyses: The PRISMA StatementThe PRISMA Statement. Ann Intern Med. 2009;151(4):264-9. doi:10.7326/ 0003-4819-151-4-200908180-00135.

48. Chi CW, Frydenberg E. Coping in the cyberworld: Program implementation and evaluation-A pilot project. Aust J Guid Couns. 2009;19:196-215.

49. de Souza MAM, Salum GA, Jarros RB, Isolan L, Davis R, Knijnik D, et al. Cognitive-behavioral group therapy for youths with anxiety disorders in the community: effectiveness in low and middle income countries. Behav Cogn Psychother. 2013;41:255-64. doi:10.1017/S1352465813000015.

50. Biegel GM, Brown KW, Shapiro SL, Schubert CM. Mindfulness-based stress reduction for the treatment of adolescent psychiatric outpatients: A randomized clinical trial. J Consult Clin Psychol. 2009;77(5):855-66. doi:10.1037/a0016241.

51. Michalak EE, Torres IJ, Bond DJ, Lam RW, Yatham LN. The relationship between clinical outcomes and quality of life in first-episode mania: a longitudinal analysis. Bipolar Disord. 2013;15:188-98. doi:10.1111/bdi.12049.

52. Hayes $L$, Boyd $C P$, Sewell J. Acceptance and commitment therapy for the treatment of adolescent depression: A pilot study in a psychiatric outpatient setting. Mindfulness. 2011;2:86-94.

53. Ginsburg GS, Barlow A, Goklish N, Hastings R, Baker EV, Mullany B, et al. Postpartum Depression Prevention for Reservation-Based American Indians: 
Results from a Pilot Randomized Controlled Trial. Child \& Youth Care Forum. 2012:41:229-45.

54. Falkenström F. Does psychotherapy for young adults in routine practice show similar results as therapy in randomized clinical trials? Psychother Res. 2010;20:181-92.

55. Albright A, Michael K, Massey C, Sale R, Kirk A, Egan T. An evaluation of an interdisciplinary rural school mental health programme in Appalachia. Adv School Mental Health Promot. 2013;6(3):189-202.

56. Hall CL, Moldavsky M, Taylor J, Marriott M, Goodman R, Sayal K et al. Innovations in Practice: Piloting electronic session-by-session monitoring in child and adolescent mental health services: A preliminary study. Child Adolescent Mental Health. 2015;20(3):171-174. doi:10.1111/camh.12066.

57. Busner J, Targum SD. The Clinical Global Impressions Scale: Applying a Research Tool in Clinical Practice. Psychiatry (Edgmont). 2007;4(7):28-37.

58. Berk M, Ng F, Dodd S, Callaly T, Campbell S, Bernardo M, et al. The validity of the CGl severity and improvement scales as measures of clinical effectiveness suitable for routine clinical use. J Eval Clin Pract. 2008;14(6): 979-83. doi:10.1111/j.1365-2753.2007.00921.x.

59. Forkmann T, Scherer A, Boecker M, Pawelzik M, Jostes R, Gauggel S. The clinical global impression scale and the influence of patient or staff perspective on outcome. BMC Psychiatry. 2011;11(1):83.

60. Startup M, Jackson MC, Bendix S. The concurrent validity of the Global Assessment of Functioning (GAF). Br J Clin Psychol. 2002;41(4):417-22. doi:10.1348/014466502760387533.

61. Schennach-Wolff R, Jäger $M$, Seemüller $F$, Obermeier M, Messer T, Laux G, et al. Defining and predicting functional outcome in schizophrenia and schizophrenia spectrum disorders. Schizophr Res. 2009;113(2-3):210-7. doi:10.1016/j.schres.2009.05.032.

62. Gold LH. DSM-5 and the Assessment of Functioning: The World Health Organization Disability Assessment Schedule 2.0 (WHODAS 2.0). J Am Acad Psychiatry Law Online. 2014;42(2):173-81.

63. Barber CC, Neese DT, Coyne L, Fultz J, Fonagy P. The Target Symptom Rating: a brief clinical measure of acute psychiatric symptoms in children and adolescents. J Clin Child Adolesc Psychol. 2002;31(2):181-92.

64. Gatta M, Dal Zotto L, Nequinio G, Del Col L, Sorgato R, Ceranto G, et al. Parents of adolescents with mental disorders: Improving their caregiving experience. J Child Fam Stud. 2011;20:478-90.

65. Weitkamp K, Daniels JK, Hofmann H, Timmermann H, Romer G, Wiegand-Grefe S. Psychoanalytic psychotherapy for children and adolescents with severe depressive psychopathology: preliminary results of an effectiveness trial. Psychotherapy (Chicago, III). 2014;51:138-47. doi:10.1037/a0034178.

66. Steinberg L. Cognitive and affective development in adolescence. Trends in Cognitive Sciences. 2005;9(2):69-74. doi:10.1016/j.tics.2004.12.005.

67. Wolpert M, Deighton J, De Francesco D, Martin P, Fonagy P, Ford T. From 'reckless' to 'mindful' in the use of outcome data to inform service-level performance management: perspectives from child mental health. BMJ Qual Saf. 2014. doi:10.1136/bmjgs-2013-002557.

68. Mulye TP, Park MJ, Nelson CD, Adams SH, Irwin Jr CE, Brindis CD. Trends in adolescent and young adult health in the United States. J Adolesc Health. 2009:45(1):8-24. doi:10.1016/j.jadohealth.2009.03.013.

69. Burgess P, Pirkis J, Coombs T. Modelling candidate effectiveness indicators for mental health services. Australian New Zealand J Psychiatry. 2009;43(6): 531-8. doi:10.1080/00048670902873656.

70. Deighton J, Wolpert M. Mental health outcome measures for children and young people. London: Anna Freud Centre/UCL; 2010.

71. Hatfield D, Ogles B. Why some clinicians use outcome measures and others do not. Adm Policy Mental Health Mental Health Serv Res. 2007;34:283-91.

72. Hatfield D, Ogles B. The use of outcome measures by psychologists in clinical practice. Prof Psychol Res Pract. 2004;35:485-91.

73. Burgess P, Pirkis J, Coombs T, Rosen A. Assessing the value of existing recovery measures for routine use in Australian mental health services. Australian and New Zealand Journal of Psychiatry. 2011;45(4):267-80. doi:10.3109/00048674.2010.549996.

74. Ng F, Trauer T, Dodd S, Callaly T, Campbell S, Berk M. The validity of the 21-item version of the Depression Anxiety Stress Scales as a routine clinical outcome measure. Acta Neuropsychiatrica. 2007;19(5):304-10. doi:10.1111/j.1601-5215.2007.00217.x.

75. Miller SD, Duncan B, Brown J, Sparks J, Claud D. The outcome rating scale: A preliminary study of the reliability, validity, and feasibility of a brief visual analog measure. J Brief Ther. 2003;2(2):91-100.
76. Janse P, Boezen-Hilberdink L, van Dijk MK, Verbraak MJ, Hutschemaekers GJ. Measuring feedback from clients: The psychometric properties of the Dutch Outcome Rating Scale and Session Rating Scale. Eur J Psychol Assess. 2014; 30(2):86.

77. Duncan BL, Sparks JA, Miller SD, Bohanske RT, Claud DA. Giving youth a voice: A preliminary study of the reliability and validity of a brief outcome measure for children, adolescents, and caretakers. J Brief Ther. 2006;5:66-82.

78. Cocchi A, Meneghelli A, Preti A. Programma 2000: celebrating 10 years of activity of an Italian pilot programme on early intervention in psychosis. Aust N Z J Psychiatry. 2008:42(12):1003-12. doi:10.1080/00048670802512032.

79. Dewa CS, Zipursky RB, Chau N, Furimsky I, Collins A, Agid O, et al. Specialized home treatment versus hospital-based outpatient treatment for first-episode psychosis: a randomized clinical trial. Early Intervent Psychiatry. 2009;3:304-11. doi:10.1111/j.1751-7893.2009.00139.x.

80. Murphy BP, Stuart AH, Wade D, Cotton S, McGorry PD. Efficacy of amisulpride in treating primary negative symptoms in first-episode psychosis: a pilot study. Hum Psychopharmacol. 2006;21:511-7.

81. Ueland T, Rund BR. A controlled randomized treatment study: The effects of a cognitive remediation program on adolescents with early onset psychosis. Acta Psychiatr Scand. 2004;109:70-4.

82. Wykes T, Newton E, Landau S, Rice C, Thompson N, Frangou S. Cognitive remediation therapy (CRT) for young early onset patients with schizophrenia: an exploratory randomized controlled trial. Schizophr Res. 2007:94:221-30.

83. Uzenoff SR, Penn DL, Graham KA, Saade S, Smith BB, Perkins DO Evaluation of a multi-element treatment center for early psychosis in the United States. Soc Psychiatry Psychiatr Epidemiol. 2012;47:1607-15. doi:10.1007/s00127-011-0467-4

84. Kutcher S, Papatheodorou G, Reiter S, Gardner D. The successful pharmacological treatment of adolescents and young adults with borderline personality disorder: a preliminary open trial of flupenthixol. J Psychiatry Neurosci. 1995;20:113-8.

85. Nash L, Gorrell J, Cornish A, Rosen A, Miller V, Tennant C. Clinical outcome of an early psychosis intervention program: evaluation in a real-world context. Aust N Z J Psychiatry. 2004;38:694-701.

86. Shaw P, Sporn A, Gogtay N, Overman GP, Greenstein D, Gochman P, et al. Childhood-onset schizophrenia: A double-blind, randomized clozapineolanzapine comparison. Arch Gen Psychiatry. 2006;63:721-30.

87. Suzuki K, Awata S, Takano T, Ebina Y, Takamatsu K, Kajiwara T, et al. Improvement of psychiatric symptoms after electroconvulsive therapy in young adults with intractable first-episode schizophrenia and schizophreniform disorder. Tohoku J Exp Med. 2006;210:213-20.

88. Baksheev GN, Allott K, Jackson HJ, McGorry PD, Killackey E. Predictors of vocational recovery among young people with first-episode psychosis: findings from a randomized controlled trial. Psychiatr Rehabil J. 2012;35(6): 421-7. doi:10.1037/h0094574.

89. Dittmann RW, Meyer E, Freisleder FJ, Remschmidt H, Mehler-Wex C, Junghanss J, et al. Olanzapine in male and female adolescent patients with schizophrenia and related disorders: Minor sex differences in outcomes. J Clin Psychopharmacol. 2010;30:328-31.

90. Agid O, Arenovich T, Sajeev G, Zipursky RB, Kapur S, Foussias G, et al. An algorithm-based approach to first-episode schizophrenia: response rates over 3 prospective antipsychotic trials with a retrospective data analysis. J Clin Psychiatry. 2011;72(11):1439-44. doi:10.4088/JCP.09m05785yel.

91. Berger GE, Proffitt T-M, McConchie M, Kerr M, Markulev C, Yuen HP, et al. Dosing quetiapine in drug-naive first-episode psychosis: a controlled, double-blind, randomized, single-center study investigating efficacy, tolerability, and safety of $200 \mathrm{mg} /$ day vs. $400 \mathrm{mg} /$ day of quetiapine fumarate in 141 patients aged 15 to 25 years. J Clin Psychiatry. 2008; 69(11):1702-14.

92. Gold J, Buonopane RJ, Caggiano RA, Picciotto M, Vogeli C, Kanner NT, et al. Assessing outcomes in child psychiatry. Am J Managed Care. 2009;15:210-6.

93. McGorry PD, Nelson B, Phillips L, Yuen HP, Francey SM, Thampi A, et al. Randomized controlled trial of interventions for young people at ultra-high risk of psychosis: Twelve-month outcome. J Clin Psychiatry. 2013;74:349-56.

94. Tang C-S, Yeh C-B, Huang Y-S, Wang L-J, Chou W-J, Chou M-C, et al. Long-term effectiveness of aripiprazole in adolescents and young adults with bipolar disorder: A naturalistic study. Int I Psychiatry Clin Pract. 2010;14:252-6. doi:10.3109/13651501.2010.505345.

95. Yeh C-B, Huang Y-S, Tang C-S, Wang L-J, Chou W-J, Chou M-C, et al. Neurocognitive effects of aripiprazole in adolescents and young adults with 
schizophrenia. Nordic J Psychiatry. 2014;68:219-24. doi:10.3109/08039488. 2013.799228.

96. Asarnow JR, Baraff $L$, Berk M, Grob CS, Devich-Navarro M, Suddath R et al. An emergency department intervention for linking pediatric suicidal patients to follow-up mental health treatment. Psychiatric Services (Washington, DC). 2011;62(11):1303-9. doi:10.1176/appi.ps.62.11.1303.

97. Bickman L, Smith CM, Lambert EW, Andrade AR. Evaluation of a Congressionally Mandated Wraparound Demonstration. J Child Fam Stud. 2003;12(2):135-56.

98. Shapiro JP, Welker CJ, Jacobson BJ. A naturalistic study of psychotherapeutic methods and client in-therapy functioning in a child community setting. J Clin Child Psychol. 1997;26:385-96.

99. Shapiro JP, Welker CJ, Jacobson BJ. The Youth Client Satisfaction Questionnaire: development, construct validation, and factor structure. J Clin Child Psychol. 1997;26:87-98.

100. Rey JM, Denshire E, Wever C, Apollonov I. Three-year outcome of disruptive adolescents treated in a day program. Eur Child Adolesc Psychiatry. 1998;7:42-8.

101. Robst J, Rohrer L, Armstrong M, Dollard N, Sharrock P, Batsche C, et al. Family involvement and changes in child behavior during residential mental health treatment. Child Youth Care Forum. 2013;42:225-38.

102. Dalton R, Pellerin K, Wolfe M, Stewart L, Thibodeaux D, Clouatre A, et al. Adolescent treatment outcome in a community mental health center. Community Ment Health J. 2003;39:47-62.

103. Noser K, Bickman L. Quality indicators of children's mental health services: Do they predict improved client outcomes? J Emotion Behav Disord. 2000;8:9-18.

104. Lundh A, Forsman M, Serlachius E, Lichtenstein P, Landén M. Outcomes of child psychiatric treatment. Acta Psychiatr Scand. 2013;128:34-44. doi:10.1111/acps.12043.

105. Larzelere RE, Dinges K, Schmidt MD, Spellman DF, Criste TR, Connell P. Outcomes of residential treatment: A study of the adolescent clients of Girls and Boys Town. Child Youth Care Forum. 2001;30:175-85.

106. Tan L, Martin G. Taming the adolescent mind: preliminary report of a mindfulness-based psychological intervention for adolescents with clinical heterogeneous mental health diagnoses. Clin Child Psychol Psychiatry. 2013; 18:300-12. doi:10.1177/1359104512455182.

107. Haine RA, Brookman-Frazee L, Tsai KH, Roesch SC, Garland AF. Clinician perspectives of diagnosis and perceived client change in 'real world' psychotherapy for youth emotional and behavioral disorders. J Child Fam Stud. 2007;16:712-28.

108. Garland AF, Aarons GA, Hawley KM, Hough RL. Relationship of youth satisfaction with mental health services and changes in symptoms and functioning. Psychiatric Serv (Washington, DC). 2003;54:1544-6.

109. Tonge BJ, Pullen JM, Hughes GC, Beaufoy J. Effectiveness of psychoanalytic psychotherapy for adolescents with serious mental illness: 12 month naturalistic follow-up study. Aust N Z J Psychiatry. 2009;43:467-75.

110. Garland AF, Haine RA, Boxmeyer CL. Determinates of youth and parent satisfaction in usual care psychotherapy. Eval Program Plann. 2007;30:45-54.

111. Bickman L, Andrade AR, Lambert EW. Dose response in child and adolescent mental health services. Ment Health Serv Res. 2002;4(2):57-70.

112. Blackman M, Pitcher S, Rauch F. A preliminary outcome study of a community group treatment programme for emotionally disturbed adolescents. Can J Psychiatry. 1986;31(2):112-8.

113. Drilea SK, Jowers K, Lichtenstein C, Hale M, Blau G, Stromberg S. Psychotropic medication use and clinical outcomes among children and adolescents receiving system of care services. J Child Adolesc Psychopharmacol. 2013;23:36-43.

114. Halliday-Boykins CA, Henggeler SW, Rowland MD, Delucia C. Heterogeneity in youth symptom trajectories following psychiatric crisis: predictors and placement outcome. J Consult Clin Psychol. 2004;72:993-1003

115. Melvin GA, Tonge BJ, King NJ, Heyne D, Gordon MS, Klimkeit E. A comparison of cognitive-behavioral therapy, sertraline, and their combination for adolescent depression. J Am Acad Child Adolesc Psychiatry. 2006;45:1151-61.

116. Milin R, Coupland K, Walker S, Fisher-Bloom E. Outcome and follow-up study of an adolescent psychiatric day treatment school program. J Am Acad Child Adolesc Psychiatry. 2000;39:320-8.

117. Tan L, Martin G. Taming the adolescent mind: A randomised controlled trial examining clinical efficacy of an adolescent mindfulness-based group programme. Child Adolescent Mental Health. 2015;20(1):49-55. doi:10.1111/ camh.12057.
118. Vishnevsky T, Strompolis M, Reeve CL, Kilmer RP, Cook JR. Using latent growth curve modeling to examine changes in mental health outcomes for children enrolled in a system of care. Am J Orthopsychiatry. 2012;82:121-8. doi:10.1111/j.1939-0025.2011.01131.x.

119. Leggero C, Masi G, Brunori E, Calderoni S, Carissimo R, Maestro S, et al. Low-dose olanzapine monotherapy in girls with anorexia nervosa, restricting subtype: focus on hyperactivity. J Child Adolesc Psychopharmacol. 2010;20:127-33. doi:10.1089/cap.2009.0072.

120. Zwaanswijk M, Verhaak PFM, van der Ende J, Bensing JM, Verhulst FC. Change in children's emotional and behavioural problems over a one-year period: Associations with parental problem recognition and service use. Eur Child Adolesc Psychiatry. 2006;15:127-31.

121. Greenbaum PE, Dedrick RF, Friedman RM, Kutash K, Brown EC, Lardieri SP, et al. National Adolescent and Child Treatment Study (NACTS): Outcomes for children with serious emotional and behavioral disturbance. J Emotion Behav Disord. 1996;4:130-46.

122. Mitchelson MR, Erskine HE, Ramirez E, Suleman F, Prasad-Ildes R, Siskind D, et al. BRiTA Futures: A resilience-building program for children and young people from culturally and linguistically diverse backgrounds-Program description and preliminary findings. Adv Mental Health. 2010;9:243-54.

123. Caldeira KM, O'Grady KE, Vincent KB, Arria AM. Marijuana use trajectories during the post-college transition: Health outcomes in young adulthood. Drug Alcohol Depend. 2012;125:267-75.

124. Patterson LJM. Long-term unemployment amongst adolescents: A longitudinal study. J Adolesc. 1997;20:261-80

125. Shek DTL. Paternal and Maternal Influences on the Psychological Well-Being, Substance Abuse, and Delinquency of Chinese Adolescents Experiencing Economic Disadvantage. J Clin Psychol. 2005;61:219-34.

126. Creed PA, Muller J, Patton W. Leaving high school: The influence and consequences for psychological well-being and career-related confidence. J Adolesc. 2003;26:295-311.

127. Graetz B. Health consequences of employment and unemployment: Longitudinal evidence for young men and women. Soc Sci Med. 1993;36: $715-24$

128. Jackson PR, Stafford EM, Banks MH, Warr PB. Unemployment and psychological distress in young people: The moderating role of employment commitment. J Appl Psychol. 1983;68:525-35.

129. Shek DTL. Paternal and maternal influences on the psychological well-being of Chinese adolescents. Genet Soc Gen Psychol Monogr. 1999;125:269-96.

130. Kohn M, Hitch D, Stagnitti K. Better Access to Mental Health program: influence of mental health occupational therapy. Aust Occup Ther J. 2012; 59:437-44. doi:10.1111/1440-1630.12005.

131. Hides LM, Elkins KS, Scaffidi A, Cotton SM, Carroll S, Lubman DI. Does the addition of integrated cognitive behaviour therapy and motivational interviewing improve the outcomes of standard care for young people with comorbid depression and substance misuse? Med J Aust. 2011;195:S31-S7.

132. Glozier N, Martiniuk A, Patton G, Ivers R, Li Q, Hickie I, et al. Short sleep duration in prevalent and persistent psychological distress in young adults: The DRIVE study. Sleep. 2010;33:1139-45.

133. Ames CS, Richardson J, Payne S, Smith P, Leigh E. Innovations in Practice: Mindfulness-based cognitive therapy for depression in adolescents. Child Adolesc Mental Health. 2014;19(1):74-8.

134. Day C, Michelson D, Hassan I. Child and adolescent service experience (ChASE): measuring service quality and therapeutic process. $\mathrm{Br} \mathrm{J}$ Clin Psychol. 2011;50:452-64. doi:10.1111/j.2044-8260.2011.02008.x.

135. Power L, Morgan S, Byrne S, Boylan C, Carthy A, Crowley S et al. A pilot study evaluating a support programme for parents of young people with suicidal behaviour. Child and Adolescent Psychiatry and Mental Health. 2009;3:20. doi: 10.1186/1753-2000-3-20.

136. Cooper M, Rowland N, McArthur K, Pattison S, Cromarty K, Richards K. Randomised controlled trial of school-based humanistic counselling for emotional distress in young people: feasibility study and preliminary indications of efficacy. Child Adolescent Psychiatry Mental Health. 2010;4: 12-. doi:10.1186/1753-2000-4-12.

137. Abeles P, Verduyn C, Robinson A, Smith P, Yule W, Proudfoot J. Computerized CBT for adolescent depression ("Stressbusters") and its initial evaluation through an extended case series. Behav Cognit Psychother. 2009;37(2):151-65. doi:10.1017/S1352465808005067.

138. Hazell PL, Martin G, McGill K, Kay T, Wood A, Trainor G, et al. Group therapy for repeated deliberate self-harm in adolescents: failure of replication of a 
randomized trial. J Am Acad Child Adolesc Psychiatry. 2009;48:662-70. doi:10.1097/CHI.0b013e3181aOacec.

139. Ougrin D, Zundel T, Ng A, Banarsee R, Bottle A, Taylor E. Trial of Therapeutic Assessment in London: randomised controlled trial of Therapeutic Assessment versus standard psychosocial assessment in adolescents presenting with self-harm. Arch Dis Childhood. 2011;96:148-53. doi:10.1136/adc.2010.188755.

140. McElearney A, Adamson G, Shevlin M, Bunting B. Impact evaluation of a school-based counselling intervention in Northern Ireland: Is it effective for pupils who have been bullied? Child Care Pract. 2013;19:4-22

141. Rajmil L, Palacio-Vieira JA, Herdman M, López-Aguilà S, Villalonga-Olives E, Valderas JM et al. Effect on health-related quality of life of changes in mental health in children and adolescents. Health And Quality Of Life Outcomes. 2009;7:103. doi:10.1186/1477-7525-7-103.

142. Sagatun A, Lien L, Søgaard AJ, Bjertness E, Heyerdahl S. Ethnic Norwegian and ethnic minority adolescents in Oslo, Norway. A longitudinal study comparing changes in mental health. Soc Psychiatry Psychiatric Epidemiol. 2008; $43: 87-95$.

143. Gunther N, Drukker M, Feron F, van Os J. No ecological effect modification of the association between negative life experiences and later psychopathology in adolescence: A longitudinal community study in adolescents. Eur Psychiatry. 2007;22:296-304.

144. Panter-Brick C, Goodman A, Tol W, Eggerman M. Mental health and childhood adversities: a longitudinal study in Kabul, Afghanistan. J Am Acad Child Adolesc Psychiatry. 2011;50:349-63. doi:10.1016/j.jaac.2010.12.001.

145. Villalonga-Olives E, Forero CG, Erhart M, Palacio-Vieira JA, Valderas JM, Herdman M, et al. Relationship between life events and psychosomatic complaints during adolescence/youth: a structural equation model approach. J Adolesc Health. 2011;49:199-205. doi:10.1016/j.jadohealth.2010. 11.260.

146. Dew-Reeves SE, Athay MM, Kelley SD. Validation and use of the Children's Hope Scale-revised PTPB edition (CHS-PTPB): high initial youth hope and elevated baseline symptomatology predict poor treatment outcomes. Adm Policy Mental Health. 2012:39:60-70. doi:10.1007/s10488-012-0411-2.

147. Ma JLC, Lai K. Applicability of family therapy for Chinese children and adolescents suffering from anorexia nervosa in a Chinese context: A preliminary study. Soc Work Mental Health. 2009;7:402-23.

148. Brown KW, West AM, Loverich TM, Biegel GM. Assessing adolescent mindfulness: Validation of an Adapted Mindful Attention Awareness Scale in adolescent normative and psychiatric populations. Psychol Assess. 2011; 23(4):1023-33.

149. Ronan GF, Dreer $L E$, Dollard KM. Measuring patient symptom change on rural psychiatry units: utility of the symptom checklist-90 revised. J Clin Psychiatry. 2000;61:493-7.

150. Schuppert HM, Timmerman ME, Bloo J, van Gemert TG, Wiersema HM, Minderaa RB et al. Emotion regulation training for adolescents with borderline personality disorder traits: a randomized controlled trial. Journal Of The American Academy Of Child And Adolescent Psychiatry. 2012;51: 1314-23.e2. doi:10.1016/j.jaac.2012.09.002.

151. Sibinga EMS, Perry-Parrish C, Chung S-E, Johnson SB, Smith M, Ellen JM. School-based mindfulness instruction for urban male youth: a small randomized controlled trial. Prev Med. 2013;57:799-801. doi:10.1016/j. ypmed.2013.08.027.

152. Bjornelv S, Nordahl HM, Holmen TL. Psychological factors and weight problems in adolescents. The role of eating problems, emotional problems, and personality traits: the Young-HUNT study. Soc Psychiatry Psychiatric Epidemiol. 2011;46:353-62. doi:10.1007/s00127-010-0197-z.

153. Pinquart M. Moderating effects of dispositional resilience on associations between hassles and psychological distress. J Appl Dev Psychol. 2009; 30:53-60.

154. Ge X, Conger RD. Adjustment problems and emerging personality characteristics from early to late adolescence. Am J Community Psychol. 1999;27:429-59.

155. Derdikman-Eiron R, Indredavik MS, Bakken IJ, Bratberg GH, Hjemdal O, Colton M. Gender differences in psychosocial functioning of adolescents with symptoms of anxiety and depression: longitudinal findings from the Nord-Trøndelag Health Study. Soc Psychiatry Psychiatric Epidemiol. 2012;47: 1855-63. doi:10.1007/s00127-012-0492-y.

156. Baruch $\mathrm{G}$. Evaluating the outcome of a community-based psychoanalytic psychotherapy service for young people between 12 and 25 years old: Work in progress. Psychoanalytic Psychother. 1995;9(3):243-67.
157. Chanen AM, Jackson HJ, McCutcheon LK, Jovev M, Dudgeon P, Yuen HP, et al. Early intervention for adolescents with borderline personality disorder using cognitive analytic therapy: Randomised controlled trial. Br J Psychiatry. 2008;193(6):477-84.

158. Schuppert HM, Giesen-Bloo J, van Gemert TG, Wiersema HM, Minderaa RB, Emmelkamp PMG, et al. Effectiveness of an emotion regulation group training for adolescents—A randomized controlled pilot study. Clin Psychol Psychother. 2009;16:467-78.

159. Kleinrahm R, Keller F, Lutz K, Kölch M, Fegert JM. Assessing change in the behavior of children and adolescents in youth welfare institutions using goal attainment scaling. Child Adolescent Psychiatry Mental Health. 2013;7: 33. doi:10.1186/1753-2000-7-33.

160. Chanen AM, Jackson HJ, McCutcheon LK, Jovev M, Dudgeon P, Yuen HP, et al. Early intervention for adolescents with borderline personality disorder: Quasi-experimental comparison with treatment as usual. Aust N Z J Psychiatry. 2009:43(5):397-408

161. Bhola P, Kapur M. Brief supportive psychotherapy with emotionally disturbed adolescent girls. NIMHANS J. 1999;17(2):131-47.

162. Nabors LA, Reynolds MW. Program evaluation activities: Outcomes related to treatment for adolescents receiving school-based mental health services. Children's Serv. 2000;3:175-89.

163. van Oort FVA, Joung IMA, Mackenbach JP, Verhulst FC, Bengi-Arslan L, Crijnen AAM, et al. Development of ethnic disparities in internalizing and externalizing problems from adolescence into young adulthood. J Child Psychol Psychiatry. 2007:48:176-84.

164. Ferdinand RF, Verhulst FC, Wiznitzer M. Continuity and change of selfreported problem behaviors from adolescence into young adulthood. J Am Acad Child Adolesc Psychiatry. 1995;34:680-90.

165. Mueller CW, Tolman R, Higa-McMillan CK, Daleiden EL. Longitudinal predictors of youth functional improvement in a public mental health system. J Behav Health Serv Res. 2010;37:350-62.

166. Tolman RT, Mueller CW, Daleiden EL, Stumpf RE, Pestle SL. Outcomes from multisystemic therapy in a statewide system of care. J Child Fam Stud. 2008; 17:894-908.

167. Preyde M, Frensch K, Cameron G, Hazineh L, Riosa PB. Mental health outcomes of children and youth accessing residential programs or a homebased alternative. Soc Work Mental Health. 2011;9:1-21.

168. Nakamura BJ, Daleiden EL, Mueller CW. Validity of treatment target progress ratings as indicators of youth improvement. J Child Fam Stud. 2007;16:729-41.

169. Emslie GJ, Hughes CW, Crismon ML, Lopez M, Pliszka S, Toprac MG, et al. A feasibility study of the childhood depression medication algorithm: the Texas Children's Medication Algorithm Project (CMAP). J Am Acad Child Adolesc Psychiatry. 2004;43:519-27.

170. Ayton A, Keen C, Lask B. Pros and cons of using the Mental Health Act for severe eating disorders in adolescents. Eur Eat Disord Rev. 2009;17(1):14-23. doi:10.1002/erv.887.

171. Duffy F, Skeldon J. A CAMHS Intensive Treatment Service: Clinical outcomes in the first year. Clin Child Psychol Psychiatry. 2014;19:90-9.

172. McShane G, Bazzano C, Walter G, Barton G. Outcome of patients attending a specialist educational and mental health service for social anxiety disorders. Clin Child Psychol Psychiatry. 2007;12:117-24.

173. Waslick BD, Walsh BT, Greenhill LL, Eilenberg M, Capasso L, Lieber D. Open trial of fluoxetine in children and adolescents with dysthymic disorder or double depression. J Affect Disord. 1999;56:227-36.

174. Jacobs B, Green J, Kroll L, Tobias C, Dunn G, Briskman J. The effect of inpatient care on measured Health Needs in children and adolescents. J Child Psychol Psychiatry Allied Disc. 2009;50:1273-81. doi:10.1111/j. 1469-7610.2009.02093.x.

175. Corrigall R, Mitchell B. Service innovations: Rethinking in-patient provision for adolescents: A report from a new service. Psychiatric Bull. 2002;26:388-92.

176. Valderhaug R, Larsson B, Götestam KG, Piacentini J. An open clinical trial of cognitive-behaviour therapy in children and adolescents with obsessivecompulsive disorder administered in regular outpatient clinics. Behav Res Ther. 2007:45:577-89.

177. Pandina G, Kushner S, Karcher K, Haas M. An open-label, multicenter evaluation of the long-term safety and efficacy of risperidone in adolescents with schizophrenia. Child And Adolescent Psychiatry And Mental Health. 2012;6:23. doi:10.1186/1753-2000-6-23.

178. Wiggins A, Oakley Browne M, Bearsley-Smith C, Villanueva E. Depressive disorders among adolescents managed in a child and adolescent mental 
health service. Australas Psychiatry. 2010;18:134-41. doi:10.3109/ 10398560903296657

179. Baker KD, Lubman DI, Cosgrave EM, Killackey EJ, Yuen HP, Hides L, et al. Impact of co-occurring substance use on 6 month outcomes for young people seeking mental health treatment. Aust N Z J Psychiatry. 2007;41(11): 896-902.

180. Mufson L, Dorta KP, Wickramaratne P, Nomura Y, Olfson M, Weissman MM. A randomized effectiveness trial of interpersonal psychotherapy for depressed adolescents. Arch Gen Psychiatry. 2004;61:577-84.

181. Goodyer IM, Dubicka B, Wilkinson P, Kelvin R, Roberts C, Byford S, et al. A randomised controlled trial of cognitive behaviour therapy in adolescents with major depression treated by selective serotonin reuptake inhibitors. The ADAPT trial. Health Technol Assess (Winchester, England). 2008;12:iii.

182. Güvenir T, Varol Taş F, Özbek A. Child and adolescent mental health inpatient services in Turkey: Is there a need and are they effective? Arch Neuropsychiatry. 2009;46:143-8.

183. Endicott J, Nee J, Yang R, Wohlberg C. Pediatric Quality of Life Enjoyment and Satisfaction Questionnaire (PQ-LES-Q): reliability and validity. J Am Acad Child Adolesc Psychiatry. 2006;45:401-7.

184. Stewart M, DelBello MP, Versavel M, Keller D. Psychosocial functioning and health-related quality of life in children and adolescents treated with open-label ziprasidone for bipolar mania, schizophrenia, or schizoaffective disorder. J Child Adolesc Psychopharmacol. 2009;19:635-40. doi:10.1089/cap. 2008.0158.

185. Kymissis P, Christenson E, Swanson AJ, Orlowski B. Group treatment of adolescent inpatients: A pilot study using a structured therapy approach. J Child Adolesc Group Ther. 1996;6:45-52.

186. Turkiewicz G, Pinzon V, Lock J, Fleitlich-Bilyk B. Feasibility, acceptability, and effectiveness of family-based treatment for adolescent anorexia nervosa: an observational study conducted in Brazil. Revista Brasileira De Psiquiatria (São Paulo, Brazil: 1999). 2010;32:169-72.

187. Merry SN, Stasiak K, Shepherd M, Frampton C, Fleming T, Lucassen MFG. The effectiveness of SPARX, a computerised self help intervention for adolescents seeking help for depression: randomised controlled non-inferiority trial. BMJ (Clinical Research Ed). 2012;344:e2598-e. doi:10.1136/bmj.e2598.

188. Lewin AB, Peris TS, De Nadai AS, McCracken JT, Piacentini J. Agreement between therapists, parents, patients, and independent evaluators on clinical improvement in pediatric obsessive-compulsive disorder. J Consult Clin Psychol. 2012;80:1103-7.

189. Alderman J, Wolkow R, Fogel IM. Drug concentration monitoring with tolerability and efficacy assessments during open-label, long-term sertraline treatment of children and adolescents. J Child Adolesc Psychopharmacol. 2006:16(1-2):117-29.

190. Bostic JQ, Prince J, Brown K, Place S. A retrospective study of citalopram in adolescents with depression. J Child Adolesc Psychopharmacol. 2001;11(2): 159-66.

191. Cook EH, Wagner KD, March JS, Biederman J, Landau P, Wolkow R, et al. Long-term sertraline treatment of children and adolescents with obsessivecompulsive disorder. J Am Acad Child Adolesc Psychiatry. 2001;40:1175-81.

192. Neziroglu F, Yaryura-Tobias JA, Walz J, McKay D. The effect of fluvoxamine and behavior therapy on children and adolescents with obsessive-compulsive disorder. J Child Adolesc Psychopharmacol. 2000;10:295-306.

193. Isolan L, Pheula G, Salum Jr GA, Oswald S, Rohde LA, Manfro GG. An open-label trial of escitalopram in children and adolescents with social anxiety disorder. J Child Adolesc Psychopharmacol. 2007;17:751-60. doi:10.1089/cap.2007.0007.

194. Straub J, Sproeber N, Plener PL, Fegert JM, Bonenberger M, Koelch MG. A brief cognitive-behavioural group therapy programme for the treatment of depression in adolescent outpatients: a pilot study. Child Adolescent Psychiatry Mental Health. 2014;8:9. doi:10.1186/1753-2000-8-9.

195. Parellada M, Fraguas D, Bombín I, Otero S, Castro-Fornieles J, Baeza I, et al. Insight correlates in child- and adolescent-onset first episodes of psychosis: results from the CAFEPS study. Psychol Med. 2009:39:1433-45. doi:10.1017/ S0033291708004868

196. Richardson L, McCauley E, Katon W. Collaborative care for adolescent depression: a pilot study. Gen Hosp Psychiatry. 2009;31:36-45. doi:10.1016/j. genhosppsych.2008.09.019.

197. Bastiaens L, Bastiaens J. Severely Mood-disordered Youth Respond Less Well to Treatment in a Community Clinic than Youth with Bipolar Disorder. Psychiatry (Edgmont (Pa: Township)). 2008;5(10):37-41.
198. Bastiaens L. Adolescents' Response to Antidepressant Treatment in a Community Mental Health Center. Community Ment Health J. 2005;41(1): $77-84$.

199. Granö N, Karjalainen M, Anto J, Itkonen A, Edlund V, Roine M. Associations between number of different type of care meetings with social network and improvement in mental well-being in adolescents at risk of first-episode psychosis. Early Interv Psychiatry. 2011;5:212-8. doi:10.1111/j.1751-7893.2011.00269.x.

200. Cornblatt BA, Auther AM, Niendam T, Smith CW, Zinberg J, Bearden CE, et al. Preliminary findings for two new measures of social and role functioning in the prodromal phase of schizophrenia. Schizophr Bull. 2007;33:688-702.

201. Granö N, Karjalainen M, Anto J, Itkonen A, Edlund V, Roine M. Intervention to improve level of overall functioning and mental condition of adolescents at high risk of developing first-episode psychosis in Finland. Early Intervent Psychiatry. 2009;3:94-8. doi:10.1111/j.1751-7893.2009.00114.x.

202. Högberg G, Hällström T. Active multimodal psychotherapy in children and adolescents with suicidality: Description, evaluation and clinical profile. Clin Child Psychol Psychiatry. 2008;13:435-48.

203. Lee YS, Lee JY, Choi TY, Choi JT. Home visitation program for detecting, evaluating and treating socially withdrawn youth in Korea. Psychiatry Clin Neurosci. 2013;67:193-202. doi:10.1111/pcn.12043.

204. Morrison AP, French P, Stewart SLK, Birchwood M, Fowler D, Gumley Al et al. Early detection and intervention evaluation for people at risk of psychosis: multisite randomised controlled trial. BMJ (Clinical Research Ed). 2012;344:e2233-e. doi:10.1136/bmj.e2233.

205. McGrew JH, Danner M. Evaluation of an intensive case management program for transition age youth and its transition to assertive community treatment. Am J Psychiatric Rehabil. 2009;12:278-94.

206. Turner MA, Boden JM, Smith-Hamel C, Mulder RT. Outcomes for 236 patients from a 2-year early intervention in psychosis service. Acta Psychiatr Scand. 2009;120:129-37. do:10.1111/j.1600-0447.2009.01386.x.

207. Mossaheb N, Schäfer MR, Schlögelhofer M, Klier CM, Cotton SM, McGorry $P D$, et al. Effect of omega-3 fatty acids for indicated prevention of young patients at risk for psychosis: when do they begin to be effective? Schizophr Res. 2013;148:163-7. doi:10.1016/j.schres.2013.05.027.

208. Schley C, Yuen K, Fletcher K, Radovini A. Does engagement with an intensive outreach service predict better treatment outcomes in 'high-risk' youth? Early Intervent Psychiatry. 2012;6:176-84. doi:10.1111/j.1751-7893. 2011.00338.x.

209. Velthorst E, Nelson B, Wiltink S, de Haan L, Wood SJ, Lin A, et al. Transition to first episode psychosis in ultra high risk populations: does baseline functioning hold the key? Schizophr Res. 2013;143:132-7. doi:10.1016/j. schres.2012.10.025.

210. Roedelof AJM, Bongers IL, van Nieuwenhuizen C. Treatment engagement in adolescents with severe psychiatric problems: a latent class analysis. Eur Child Adolesc Psychiatry. 2013;22:491-500. doi:10.1007/ s00787-013-0385-y.

211. Granö N, Karjalainen M, Edlund V, Saari E, Itkonen A, Anto J, et al. Changes in health-related quality of life and functioning ability in help-seeking adolescents and adolescents at heightened risk of developing psychosis during family- and community-oriented intervention model. Int J Psychiatry Clin Pract. 2013;17:253-8. doi:10.3109/13651501.2013.784791.

212. Halfon O, Laget J, Barrie M. An epidemiological and clinical approach to adolescent suicide. A comparison between suicidal and non-suicidal clinical groups in a health foundation center for French students. Eur Child Adolesc Psychiatry. 1995;4:32-8.

213. Haggerty $G$, Kahoud D, Walsh E, Ahmed Z, Blais MA. A brief inpatient measure of global psychiatric symptom severity: initial validation of the Brief Symptom Measure-25 for an adolescent inpatient sample. J Nerv Mental Dis. 2013;201:971-6. doi:10.1097/NMD.0000000000000040.

214. Jardri R, Bubrovszky $M$, Demeulemeester $M$, Poulet $E$, Januel $D$, Cohen $\mathrm{D}$, et al. Repetitive transcranial magnetic stimulation to treat early-onset auditory hallucinations. J Am Acad Child Adolesc Psychiatry. 2012:51:947-9.

215. Blackman M, Eustace J, Chowdhury T. Adolescent residential treatment: a one to three year follow-up. Can J Psychiatry Revue Canadienne De Psychiatrie. 1991;36(7):472-9.

216. Bickman L, Andrade AR, Lambert EW. Dose response in child and adolescent mental health services. Ment Health Serv Res. 2002;4:57-70.

217. Feenstra DJ, Laurenssen EMP, Hutsebaut J, Verheul R, Busschbach JJV. Predictors of treatment outcome of Inpatient Psychotherapy for Adolescents 
with personality pathology. Person Mental Health. 2014;8:102-14. doi:10.1002/ pmh.1246.

218. Laurenssen EMP, Hutsebaut J, Feenstra DJ, Bales DL, Noom MJ, Busschbach $J \mathrm{JV}$, et al. Feasibility of mentalization-based treatment for adolescents with borderline symptoms: A pilot study. Psychotherapy. 2014;51:159-66.

219. Palacio-Vieira JA, Villalonga-Olives E, Valderas JM, Espallargues M, Herdman M, Berra S, et al. Changes in health-related quality of life (HRQoL) in a population-based sample of children and adolescents after 3 years of follow-up. Qual Life Res. 2008;17:1207-15. doi:10.1007/s11136-008-9405-7.

220. Villalonga-Olives E, Rojas-Farreras S, Vilagut G, Palacio-Vieira JA, Valderas JM, Herdman $\mathrm{M}$ et al. Impact of recent life events on the health related quality of life of adolescents and youths: the role of gender and life events typologies in a follow-up study. Health And Quality Of Life Outcomes. 2010; 8:71-. doi:10.1186/1477-7525-8-71.

221. McHugh MD. Readiness for change and short-term outcomes of female adolescents in residential treatment for anorexia nervosa. Int J Eating Disord. 2007:40:602-12

222. Padierna A, Quintana JM, Arostegui I, Gonzalez N, Horcajo MJ. Changes in health related quality of life among patients treated for eating disorders. Qual Life Res. 2002;11:545-52.

223. del Valle MF, Pérez M, Santana-Sosa E, Fiuza-Luces C, Bustamante-Ara N, Gallardo C, et al. Does resistance training improve the functional capacity and well being of very young anorexic patients? A randomized controlled trial. J Adolesc Health. 2010;46:352-8.

224. Nickel C, Lahmann C, Tritt K, Loew TH, Rother WK, Nickel MK. Short Communication: Stressed aggressive adolescents benefit from progressive muscle relaxation: A random, prospective, controlled trial. Stress Health. 2005;21:169-75.

225. Salonna F, Middel B, Sleskova M, Geckova AM, Reijneveld SA, Groothoff JW, et al. Deterioration is not the only prospect for adolescents' health: improvement in self-reported health status among boys and girls from age 15 to age 19. Croat Med J. 2008;49:66-74.

226. Asarnow JR, Jaycox LH, Duan N, LaBorde AP, Rea MM, Murray P, et al. Effectiveness of a quality improvement intervention for adolescent depression in primary care clinics: a randomized controlled trial. JAMA. 2005:293:311-9.

227. Asarnow JR, Jaycox LH, Tang L, Duan N, LaBorde AP, Zeledon LR, et al. Long-term benefits of short-term quality improvement interventions for depressed youths in primary care. Am J Psychiatry. 2009;166(9):1002-10. doi:10.1176/appi.ajp.2009.08121909.

228. Ngo VK, Asarnow JR, Lange J, Jaycox LH, Rea MM, Landon C et al. Outcomes for youths from racial-ethnic minority groups in a quality improvement intervention for depression treatment. Psychiatric Services (Washington, DC). 2009;60:1357-64. doi:10.1176/appi.ps.60.10.1357.

229. Reid SC, Kauer SD, Hearps SJC, Crooke AHD, Khor AS, Sanci LA et al. A mobile phone application for the assessment and management of youth mental health problems in primary care: a randomised controlled trial. BMC Fam Pract. 2011;12:131. doi:10.1186/1471-2296-12-131.

230. Ritchie SD, Wabano MJ, Russell K, Enosse L, Young NL. Promoting resilience and wellbeing through an outdoor intervention designed for Aboriginal adolescents. Rural Remote Health. 2014;14:2523.

231. Adamis D, Giannakopoulou DF, Konstantopoulou A, Michailides M. Translation and standardization of the HoNOSCA (Health of the Nation Outcome Scales for Children and Adolescents) scale in a Greek sample. Clin Child Psychol Psychiatry. 2011;16(4):567-73. doi:10.1177/1359104510387881.

232. Bobier C, Dowell J, Swadi H. An examination of frequent nursing interventions and outcomes in an adolescent psychiatric inpatient unit. Int J Mental Health Nurs. 2009;18(5):301-9. doi:10.1111/.j.1447-0349.2009.00618.x.

233. Hanssen-Bauer K, Heyerdahl S, Hatling T, Jensen G, Olstad PM, Stangeland T et al. Admissions to acute adolescent psychiatric units: a prospective study of clinical severity and outcome. Int J Mental Health Syst. 2011;5:1. doi:10. 1186/1752-4458-5-1.

234. Lesinskiene S, Senina J, Ranceva N. Use of the HoNOSCA scale in the teamwork of inpatient child psychiatry unit. J Psychiatric Mental Health Nurs. 2007;14:727-33.

235. Gowers S, Levine W, Bailey-Rogers S, Shore A, Burhouse E. Use of a rotuine, self-report outcome measure (HoNOSCA-SR) in two adolescent mental health servies. Br J Psychiatry. 2002;180:266-9.

236. Holzer L, Tchemadjeu IK, Plancherel B, Bolognini M, Rossier V, Chinet L, et al. Adolescent Drug Abuse Diagnosis (ADAD) vs. Health of Nation Outcome
Scale for Children and Adolescents (HoNOSCA) in clinical outcome measurement. J Eval Clin Pract. 2006;12:482-90.

237. Harnett PH, Loxton NJ, Sadler T, Hides L, Baldwin A. The Health of the Nation Outcome Scales for Children and Adolescents in an adolescent in-patient sample. Aust N Z J Psychiatry. 2005;39:129-35.

238. Gowers SG, Clark A, Roberts C, Griffiths A, Edwards V, Bryan C, et al. Clinical effectiveness of treatments for anorexia nervosa in adolescents: randomised controlled trial. Br J Psychiatry. 2007;191:427-35.

239. Swadi H, Bobier C. Hospital admission in adolescents with acute psychiatric disorder: how long should it be? Australas Psychiatry. 2005;13:165-8.

240. Gowers SG, Clark AF, Roberts C, Byford S, Barrett B, Griffiths A et al. $A$ randomised controlled multicentre trial of treatments for adolescent anorexia nervosa including assessment of cost-effectiveness and patient acceptability - the TOuCAN trial. Health Technol Assess(Winchester, England). 2010;14:1-98. do:10.3310/hta14150.

241. Green JM, Wood AJ, Kerfoot MJ, Trainor G, Roberts C, Rothwell J, et al. Group therapy for adolescents with repeated self harm: Randomised controlled trial with economic evaluation. BMJ. 2011;342:1-12.

242. Karpenko V, Owens JS. Adolescent psychotherapy outcomes in community mental health: how do symptoms align with target complaints and perceived change? Community Ment Health J. 2013;49:540-52. doi:10.1007/s10597-012-9515-0

243. Ogles BM, Melendez G, Davis DC, Lunnen KM. The Ohio Scales: Practical outcome assessment. J Child Fam Stud. 2001;10:199-212.

244. Turchik JA, Karpenko V, Ogles BM, Demireva P, Probst DR. Parent and adolescent satisfaction with mental health services: Does it relate to youth diagnosis, age, gender, or treatment outcome? Community Ment Health J. 2010:46:282-8

245. McKenzie K, Murray GC, Prior S, Stark L. An evaluation of a school counselling service with direct links to Child and Adolescent Mental Health (CAMH) services. Br J Guidance Counsell. 2011:39:67-82.

246. Cannon JAN, Warren JS, Nelson PL, Burlingame GM. Change trajectories for the Youth Outcome Questionnaire self-report: identifying youth at risk for treatment failure. J Clin Child Adolesc Psychol. 2010;39(3):289-301. doi:10.1080/15374411003691727.

247. Warren JS, Nelson PL, Mondragon SA, Baldwin SA, Burlingame GM. Youth psychotherapy change trajectories and outcomes in usual care: Community mental health versus managed care settings. J Consult Clin Psychol. 2010; 78:144-55. doi:10.1037/a0018544.

248. Michael KD, Albright A, Jameson JP, Sale R, Massey C, Kirk A, et al. Does cognitive behavioural therapy in the context of a rural school mental health programme have an impact on academic outcomes? Adv School Mental Health Promot. 2013;6:247-62.

\section{Submit your next manuscript to BioMed Central and take full advantage of:}

- Convenient online submission

- Thorough peer review

- No space constraints or color figure charges

- Immediate publication on acceptance

- Inclusion in PubMed, CAS, Scopus and Google Scholar

- Research which is freely available for redistribution 